\section{LA INTERRELACIÓN ENTRE EL JUEZ Y EL ÁRBITRO INTERNACIONAL. ESTUDIO COMPARATIVO ENTRE FRANCIA Y COLOMBIA*}

\author{
THE INTERRELATION AMONG JUDGES AND THE \\ INTERNATIONAL ARBITERS. COMPARATIVE \\ STUDY BETWEEN FRANCE \& COLOMBIA
} A INTER-RELAÇÃO ENTRE 0 JUIZ E 0 ÁRBITRO
INTERNACIONAL. ESTUDO COMPARATIVO ENTRE
A FRANÇA E A COLÔMBIA

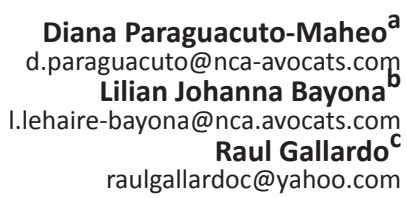

Fecha de recepción: 21 de Mayo 2014 Fecha de revisión:11 de Septiembre 2014 Fecha de aceptación: 16 de Septiembre 2014

\title{
RESUMEN
}

Con la entrada en vigencia de la Ley 1563 de 2012, Colombia decidió modernizar su sistema legal de arbitraje nacional e internacional. De manera general el texto incorpora dentro de sus disposiciones una nueva visión del arbitraje, la cual ha sido adoptada por la mayoría de los países con sistemas de arbitraje más desarrollados. A partir de la experiencia francesa en la práctica del arbitraje, la cual ha sido impulsada y sostenida por el trabajo de los jueces, el objeto de nuestro estudio es analizar la manera cómo

\footnotetext{
* Artículo de Investigación basado en el ejercicio académico y profesional de los autores con el fin de establecer un estudio comparativo que sirva de herramienta practica para comprender el desarrollo del arbitraje desde una óptica nacional e internacional.

a. Abogada asociada en el bufete Ngo Cohen Amir Aslani en París, inscrita en las Barras de Paris, New York y Madrid. Mediadora de la CEDR y árbitro internacional, especialista en contencioso internacional, arbitraje y modos alternativos de resolución de conflictos, miembro del comité de arbitraje de la CCI, encargada de estudios de la escuela de formación de la barra de París.

b. Abogada egresada de la Universidad Autónoma de Bucaramanga. Especialización en Derecho Internacional y Europeo, Universidad París Descartes, Francia. Master II en Negocios Internacionales, Universidad París Descartes. Jurista de negocios internacionales. Abogada Asesora y consultora.

c. Abogado egresado de la Universidad del Rosario. Especialización en Derecho Civil, Universidad de Paris II Panthéon-Assas, Francia. Master II en Derecho Privado General, Universidad de Paris II Panthéon-Assas, Francia. Master II en Arbitraje y Comercio Internacional, Universidad de Versalles St Quentin en Yvelines, Francia. Aprobación examen de abogado en Francia. Abogado asesor y consultor.
}

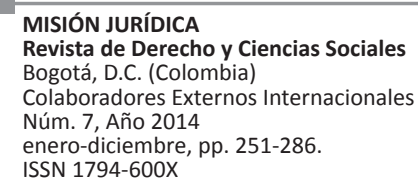


se articula la colaboración entre los jueces y los árbitros a lo largo del procedimiento arbitral. ¿Existe realmente en Colombia un clima general favorable al arbitraje, que pueda permitirle erigirse como una destinación importante en el arbitraje latinoamericano?, o ¿será necesario adoptar medidas que puedan conducir al mejoramiento de sus sistema, para situarlo en la vanguardia de las legislaciones internacionales pioneras en la materia?

\section{PALABRAS CLAVE}

Arbitraje internacional, autoridad judicial, juez de apoyo, Tribunal arbitral.

\begin{abstract}
A new legislation for international and domestic arbitration has entered into force in Colombia as an attempt to modernize and improve the arbitration framework that had been established by law and practice. The 1563 Law of 2012 introduces in Colombia a new approach to arbitration, one that has been adopted in countries with more developed arbitration systems. The 1562 Law is not all revolutionary. It also confirms what had been case law in Colombia for many years. This paper is an attempt to analyze the 1562 Law and the supporting role given to the judiciary system through a comparison with the French legal framework. Indeed, the recently enacted decree in France introduces the figure of the juge d'appui, thereby reinforcing the already supporting role of arbitration in this country. Reading Colombian Law 1563 through the prism of France' experience in arbitration could provide us with new insights and help us determine how our judges should act to foster Clombia as a place of international arbitration.
\end{abstract}

\section{KEYWORDS}

International and domestic arbitration, support judge, judicial authority, arbitrary tribunal.

\section{RESUMO}

Com a promulgação da Lei 1.563 de 2012, a Colômbia decidiu modernizar seu sistema jurídico da arbitragem nacional e internacional. Geralmente, o texto incorpora em suas disposições uma nova visão da arbitragem que tem sido adotada pela maioria dos países com sistemas mais desenvolvidos de arbitragem. A partir da experiência francesa na prática da arbitragem, que foi dirigida e sustentada pelo trabalho dos juízes, o objeto de nosso estudo é analisar a maneira como a colaboração entre juízes e árbitros estão articuladas ao longo dos processos de arbitragem. Na Colômbia existe realmente um clima geral favorável à arbitragem que pode permitir estabelecer-se como um dos principais destinos na arbitragem latino-americana?, $\mathrm{Ou}$, é necessário tomar medidas que possam levar à melhoria do seu sistema para colocá-lo na vanguarda da legislação internacional?

\section{PALAVRAS-CHAVE}

Arbitragem internacional, autoridade judicial, suporte juiz, Tribunal arbitral.

\section{INTRODUCCION}

En las últimas décadas los esfuerzos para modernizar los sistemas de arbitraje de los países latinoamericanos se han multiplicado. Colombia decidió modernizar su marco legal sobre el arbitraje nacional e internacional a través de la ley 1563 de 2012; una iniciativa que demuestra la política del país para favorecer las inversiones internacionales y la competitividad, que según los propios términos de Germán Vargas Lleras, Ministro del interior y de la Justicia del momento, tienen una estrecha relación con los servicios de la administración de la justicia. ${ }^{1}$

La Ley del 2012 se basa en la Ley Modelo sobre Arbitraje Comercial Internacional de la Comisión de las Naciones Unidas para el Derecho Mercantil Internacional (CNUDMI), la cual establece un régimen jurídico especialmente adaptado al arbitraje comercial internacional ${ }^{2}$, con algunas

1 Ministerio del interior y de la Justicia. República de Colombia. Congreso de la República. Proyecto de ley de 2011. Por medio del cual se expide el Estatuto de Arbitraje Nacional e Internacional y se dictan otras disposiciones. Disponible en: http://www.google. $\mathrm{com} / \mathrm{url}$ ?sa $=t \& r c t=j \& q=\&$ esrc $=s \&$ source $=w e b \& c d=1 \& v e d=0 C C \mathrm{k}$ QFjAA\&url=http\%3A\%2F\%2Fxa.yimg.com\%2Fkq\%2Fgroups\% 2F18041107\%2F1576947705\%2Fname\%2FPROYECTOdoc\&ei= FSIEUrfkCYTc8wSUpIGIDA\&usg=AFQjCNHdLfGjede7yR22sB5QY zp1uvAZpA\&bvm=bv.50500085, d.eWU.

2 Como ejemplo de la influencia de la Ley Modelo de la CNUDMI sobre arbitraje comercial internacional encontramos en América latina las legislaciones de países como Bolivia que acoge de manera parcial la ley modelo mediante la ley 9307 de 1996, Brasil lo hace de la misma manera, Nicaragua adopto la ley 540 
modificaciones inspiradas en las leyes francesas, suecas y suizas sobre arbitraje.

Por su parte, Francia adoptó en el año 2011 una nueva ley de arbitraje $\mathrm{e}^{3}$. El derecho francés siempre ha sido uno de los derechos más favorables al arbitraje internacional ${ }^{4}$ y su reforma continua en este sentido, consagra numerosas soluciones jurisprudenciales.

Mientras la legislación francesa, de tendencia liberal, ha sido impulsada ampliamente por el trabajo de los jueces, la legislación colombiana ha demostrado una voluntad política de adaptar su sistema de justicia, para hacer de Colombia un país más atractivo, en cuanto a los inversionistas extranjeros se refiere.

Sin embargo, la sola entrada en vigor de un nuevo cuerpo legal no es suficiente para asegurar el éxito del arbitraje. La experiencia del derecho francés ha demostrado que la interacción entre las autoridades judiciales y el árbitro, es esencial para garantizar su eficiencia y desarrollo.

De la manera como las autoridades judiciales colombianas adopten y desarrollen las nuevas disposiciones legales en materia de arbitraje internacional, dependerá el éxito del arbitraje internacional en Colombia. En su defecto, los esfuerzos legislativos serán "letras muertas" en el panorama jurídico y económico colombiano.

La evolución francesa, en materia de arbitraje, ha demostrado que el éxito del arbitraje depende de un total soporte del cuerpo jurisdiccional, antes, durante y después del proceso arbitral. Así las cosas, ¿los esfuerzos legislativos realizados con la ley de 2012 permitirán que Colombia sea una sede importante para los arbitrajes internacionales? ¿Los jueces están preparados

de 2005 "Ley de la mediación y del arbitraje”, Panamá lo hizo mediante el decreto ley número 5 del 8 de julio de 1999.

3 Ver Decreto n-2011-48 del 13 de enero del 2011 sobre la reforma del arbitraje, JO, 14 enero 2011, 777 [Decreto], modificando las disposiciones del nuevo Código de procedimiento Civil Francés, ver igualmente el reporte del Primer Ministro relativo al decreto $n^{\circ}$ 2011-48 sobre la reforma del arbitraje. JO, 14 enero 2011. 733. [Reporte del primer Ministro]. Disponible en http://www. legifrance.gouv.fr/affichTexte.do?cidTexte=JORFTEXT00002341 $7517 \&$ date Texte $=\&$ categorieLien $=i d$.

4 GAILLARD, Emmanuel y DE LAPASSE Pierre, Commentaire analytique du décret du 13 janvier 2011 portant réforme du droit français de l'arbitrage, Cahiers de l'Arbitrage (2011) 2. pag. 263. para darle al arbitraje el campo de acción que necesita para ser efectivo?

En los capítulos subsiguientes analizaremos sucesivamente el efecto negativo del principio de competencia-competencia frente a las autoridades judiciales, las facultades de los árbitros para decretar medidas cautelares y el apoyo del juez ordinario, necesario para agilizar, sobrellevar y fortalecer la eficiencia del proceso arbitral. En un tercer capítulo analizaremos el rol del juez de apoyo como soporte en el curso de la instancia arbitral $y$, finalmente, en un cuarto capítulo nos interesaremos en el ejercicio del control por parte de los jueces. En este último capítulo analizaremos adicionalmente la intervención del juez de tutela dentro del arbitraje en Colombia, factor de fragilidad, en el nuevo esquema nacional colombiano.

\section{METODOLOGÍA}

La función del juez de apoyo en las relaciones entre el sistema judicial colombiano y los tribunales de arbitramento aún no es del todo clara para los practicantes locales. Se ofrece en este estudio una comparación con la realidad francesa, amplia conocedora del fenómeno, lo cual puede permitir apreciar los avances de la materia en Colombia y aquellos que deberían venir en el futuro.

\section{INCOMPETENCIA DE LAS JURISDICCIONES NACIONALES EN PRESENCIA DE UNA CONVENCIÓN ARBITRAL}

El "acuerdo de arbitraje" es un acuerdo mediante el cual las partes deciden someter a arbitraje controversias que hayan surgido o puedan surgir entre ellas respecto de una determinada relación jurídica contractual. El acuerdo de arbitraje podrá adoptar la forma de una cláusula compromisoria incluida en un contrato o de un acuerdo independiente ${ }^{5}$.

El principio de competencia-competencia supone que sea el árbitro quien resuelva sobre las controversias del convenio arbitral y de su

5 Ley Modelo de la CNUDMI sobre Arbitraje Comercial Internacional 1985 con las enmiendas aprobadas en 2006 sobre Arbitraje Comercial Internacional. Articulo 7. Disponible en http://www.uncitral.org/pdf/spanish/texts/arbitration $/ \mathrm{ml}$ arb/07-87001_Ebook.pdf. 
propia competencia. Aunque una de las partes pueda alegar la nulidad del contrato, del cual se desprende el pacto arbitral, el árbitro tendrá la facultad de pronunciarse sobre su propia competencia. ${ }^{6}$

Esta potestad tiene como consecuencia un efecto positivo, relacionado con la competencia de los árbitros para conocer del fondo del litigio, y un efecto negativo, vinculado con la ausencia de competencia de la autoridad judicial para decidir sobre el asunto ${ }^{7}$, por haber sido el objeto de una convención arbitral. Los dos sistemas jurídicos analizados incorporan estos principios fundadores del arbitraje internacional, aunque con diferencias.

Analizaremos sucesivamente las implicaciones del efecto negativo del principio de competenciacompetencia, que impone a la autoridad judicial la obligación de reenviar a las partes a la convención arbitral, (1.1) y cómo el principio de competenciacompetencia es ejercido por los árbitros. (1.2)

\subsection{El efecto negativo de la competencia de las autoridades judiciales frente a la convención de arbitraje}

La evolución de los sistemas legales en el arbitraje internacional y las reglas instauradas por los tratados internacionales en materia de arbitraje, tales como: El Protocolo de Ginebra de 1923, relativo a las cláusulas de arbitraje; la Convención sobre el Reconocimiento y la Ejecución de las Sentencias Arbitrales Extranjeras, o Convención de New York de 1958, y la ley modelo CNUDMI, han

6 La CNUDMI (UNCITRAL) adoptó oficialmente el principio Kompetenz Kompetenz,estableciendo al respecto en el artículo 21, numeral 1: "El tribunal arbitral estará facultado para decidir acerca de las objeciones de que carece de competencia, incluso las objeciones respecto de la existencia o la validez de la cláusula compromisoria o del acuerdo de arbitraje separado". Posteriormente, en 1985, estableció en el artículo 16, numeral primero: "Facultad del tribunal arbitral para decidir acerca de su competencia.

7 Sobre las implicaciones y connotaciones del principio de competencia competencia podemos encontrar entre otros, GOMEZ JENE, Miguel. El arbitraje internacional en la Unión Europea: La eficacia del laudo arbitral, Madrid, Editorial Colex, 2000, p. 104; CADARSO PALAU, Juan. Potestad de los Árbitros para decidir sobre su Competencia. En: Comentarios a la Nueva Ley de Arbitraje 60/2003, de 23 de diciembre. Navarra. Editorial Aranzadi S.A. 2004. Páginas 265-266.; VASQUEZ PALMA, Maria Fernanda. Comprensión del principio Competencia-Competencia y configuración de la nulidad o ineficacia del acuerdo arbitral. Revista Chilena de Derecho Privado, $N^{\circ} 15$, pp. 181-196. Diciembre 2010]. consagrado el principio del efecto negativo de la competencia de las autoridades judiciales frente a una convención de arbitraje.

El artículo 4 del Protocolo de Ginebra de 1923, relativo a las cláusulas de $\operatorname{arbitraje} \mathrm{e}^{8}$, lo consagra de la siguiente manera:

4 ) Los Tribunales de los Estados contratantes, al presentárseles un litigio sobre un contrato celebrado entre personas comprendidas en el artículo 1, y que incluya acuerdo de arbitraje sobre diferencias actuales o futuras válido en virtud de dicho artículo y susceptible de aplicación, lo someterá, a petición de una de las partes, a la decisión de los árbitros.

Esta inhibición será sin perjuicio de la competencia de los tribunales en el caso de que el acuerdo de arbitraje prescriba o se anule(...).

Por su parte la convención de New York de 1958 establece el efecto negativo de la competencia-competencia en los siguientes términos ${ }^{9}$ :

\section{(...) Artículo II}

(...) 3. El tribunal de uno de los Estados Contratantes al que se someta un litigio respecto del cual las partes hayan concluido un acuerdo en el sentido del presente artículo, remitirá a las partes al arbitraje, a instancia de una de ellas, a menos que compruebe que dicho acuerdo es nulo, ineficaz o inaplicable(...).

Adicionalmente; la Ley Modelo de la CNUDMI sobre Arbitraje Comercial Internacional establece $^{10}$ :

8 Ver Protocolo de Ginebra de 1923 relativo a las cláusulas de arbitraje en materia comercial. Disponible en http://www. uncitral.org/pdf/spanish/publications/sales_publications/ Registro_textos_vol_II.pdf

9 Ver Convención de New York de 1958 sobre el reconocimiento y la ejecución de las sentencias extranjeras. Articulo II 3. Disponible en http://www.euroarbitration.org/resources/es/ nyc_convention_es.pdf

10 Ley Modelo de la CNUDMI sobre Arbitraje Comercial Internacional. Disponible en http://www.uncitral.org/pdf/ spanish/texts/arbitration/ml-arb/07-87001_Ebook.pdf 
Artículo 8. Acuerdo de arbitraje y demanda en cuanto al fondo ante un tribunal

(...) 1) El tribunal al que se someta un litigio sobre un asunto que es objeto de un acuerdo de arbitraje remitirá a las partes al arbitraje si lo solicita cualquiera de ellas, a más tardar, en el momento de presentar el primer escrito sobre el fondo del litigio, a menos que se compruebe que dicho acuerdo es nulo, ineficaz o de ejecución imposible(...) .

En estos términos, el efecto negativo del principio de competencia-competencia constriñe a las autoridades judiciales a reenviar a las partes ante un tribunal arbitral e impide que el litigio pueda ser objeto de decisión por parte de una autoridad judicial (con excepción del caso de la renuncia por parte de las partes).

Tanto la legislación francesa como la colombiana lo integran en el orden jurídico, aunque con ciertas diferencias.

La legislación francesa lo incorpora dentro de su cuerpo legislativo en el artículo 1448 del Código de Procedimiento Civil, sobre el arbitraje interno, el cual también se aplica en materia internacional:

En caso de que una controversia cubierta por un convenio arbitral se someta a un tribunal estatal, este deberá declararse incompetente, salvo si el tribunal arbitral no estuviera aún conociendo de la controversia y el convenio arbitral fuere manifiestamente nulo o manifiestamente inaplicable.

El tribunal estatal no podrá declarar de oficio su incomincompetencia ${ }^{11}(\ldots)$.

En Colombia la Ley 1563 de 2012 contempla en el artículo 70, sobre las reglas del arbitraje internacional, la obligación de reenviar a las partes ante un tribunal arbitral en presencia de una cláusula compromisoria :

11 Código de procedimiento civil francés. Artículo 1448. " Lorsqu'un litige relevant d'une convention d'arbitrage est porté devant une juridiction de l'Etat, celle-ci se déclare incompétente sauf si le tribunal arbitral n'est pas encore saisi et si la convention d'arbitrage est manifestement nulle ou manifestement inapplicable.
Acuerdo de arbitraje y demanda en cuanto al fondo ante una autoridad judicial. La autoridad judicial a la que se someta un litigio sobre un asunto que es objeto de un acuerdo de arbitraje remitirá a las partes al arbitraje si lo solicita cualquiera de ellas, a más tardar, en la oportunidad para la contestación de la demanda.

No obstante haberse entablado ante la autoridad judicial la acción a que se refiere el inciso anterior, se podrán iniciar o proseguir la actuación arbitral y dictar un laudo aunque la cuestión esté pendiente ante la autoridad judicial. $^{12}$

La comparación de las dos disposiciones citadas nos permite identificar diferencias significativas. En primer lugar, la norma del derecho francés contiene la obligación en cabeza del juez de declararse incompetente cuando un litigio cubierto por una convención de arbitraje le es sometido.

El principio del efecto negativo en Francia, más allá de una regla de competencia, es una prohibición dirigida al juez de conocer de un litigio en presencia de una convención arbitral. Sin embargo, el párrafo primero del artículo 1448 impone un límite a la figura con el establecimiento de dos condiciones cumulativas que, de cumplirse, no obligarían al juez a declararse incompetente: (i) Que el tribunal arbitral no haya sido constituido; y (ii) si la convención arbitral es inaplicable o manifiestamente nula.

Con esto se intenta evitar que se obligue a una persona a acudir al arbitraje cuando puede ser manifiestamente abusivo. El parágrafo dos del artículo 1448 francés impide que el juez declare su incompetencia de manera oficiosa.

En el caso colombiano, para analizar el artículo 70 de la ley de 2012, tenemos que remitirnos inicialmente al artículo 8 de la Ley Modelo de la CNUDMI sobre el Arbitraje Comercial Internacional, el cual fue retomado por La ley de 2012.

El numeral 1 del artículo 8 de la ley modelo de arbitraje de la CNUDMI está inspirado,

12 Ley 1563 de 2012, (Julio 12) Diario Oficial No. 48.489 de 12 de julio de 2012, disponible en http://www.secretariasenado.gov. co/senado/basedoc/ley/2012/ley_1563_2012.html 
parcialmente, en el artículo II.3 de la Convención de Nueva York, el cual establece la remisión de las partes al arbitraje; tal y como ocurre en derecho francés, la solicitud de las partes es necesaria para que la autoridad judicial pueda declarar su incompetencia.

Este primera parte del artículo no deja dudas sobre el efecto negativo del convenio arbitral frente a la competencia de las autoridades judiciales. Además, el artículo 70 establece un momento preciso para que las partes puedan solicitar el reenvío del caso a un tribunal de arbitramento: a más tardar en el momento de presentación del primer escrito de contestación de la demanda, so pena de entenderse una renuncia al ejercicio del derecho.

El segundo parágrafo del artículo 70 se inspiró en la Ley Modelo de la CNUDMI ${ }^{13}$. El espíritu de este parágrafo yace en el fortalecimiento de las funciones del tribunal arbitral, dado que su conocimiento sobre el caso no se ve obstaculizado por el hecho de que el juez local no se haya pronunciado sobre la validez, la operatividad y la existencia del convenio arbitral.

Esta disposición causó polémica en las discusiones que tuvieron lugar antes de la adopción de la Ley Modelo de la CNUDMI. Algunos consideraban que se le debía dar el poder al juez local para evitar la constitución del tribunal arbitral hasta que no existiera un pronunciamiento sobre el convenio arbitral, de esta manera se evitaría la constitución de tribunales arbitrales que podrían llegar a ser inútiles.

Otros apoyaron la moción que sostenía se permitiera la constitución del tribunal arbitral, aun si el juez local no se había pronunciado, para evitar retrasos innecesarios en el proceso arbitral. Los procesos paralelos podrían contribuir a una resolución pronta del litigio y cualquier decisión de suspender el arbitraje solo podría ser tomada

13 Ley Modelo de la CNUDMI. Artículo 8: "Acuerdo de arbitraje y demanda en cuanto al fondo ante un tribunal. 1) El tribunal al que se someta un litigio sobre un asunto que es objeto de un acuerdo de arbitraje remitirá a las partes al arbitraje si lo solicita cualquiera de ellas, a más tardar, en el momento de presentar el primer escrito sobre el fondo del litigio, a menos que se compruebe que dicho acuerdo es nulo, ineficaz o de ejecución imposible. 2) Si se ha entablado la acción a que se refiere el párrafo 1) del presente artículo, se podrá, no obstante, iniciar o proseguir las actuaciones arbitrales y dictar un laudo mientras la cuestión esté pendiente. Ver referencia nota de página 10 supra. por el tribunal de arbitramento ${ }^{14}$. Esta fue, finalmente, la posición que se adoptó a favor del arbitraje en Colombia, a pesar de que la redacción cambió un poco respecto de la Ley Modelo.

El artículo 70 de la Ley 1563 no habla de la nulidad, ineficacia o ejecución imposible como casos en los cuales el juez local podría negarse a reenviar a las partes al tribunal de arbitramento, como sí lo hace la Ley Modelo. Esto podría interpretarse como otra medida a favor del arbitraje, debido a que, ni en esos casos, el juez podría negarse a cumplir con el artículo 70 . Una decisión de la Corte Constitucional del 20 de mayo de 2013 reafirma este pensamiento. La Corte Constitucional se refiere a los artículos $67^{15}, 70$ y $79^{16}$ de la ley 2012 para determinar los alcances de la intervención judicial en el proceso arbitral y concluye:

(...) Estas disposiciones normativas están encaminadas a proscribir cualquier intervención judicial que no esté orientada a apoyar el normal desarrollo del arbitraje o que no constituya un ejercicio del control judicial expresamente autorizado por el tribunal arbitral..

(...) el estatuto arbitral otorga confianza absoluta y prioritaria a los árbitros para determinar su propia competencia, lo cual se encuentra justificado en el hecho de que el juez no tiene la facultad de comprobar si el convenio arbitral es nulo, ineficaz o de ejecución imposible. Así, no se permite a los jueces realizar cualquier injerencia en la

14 HOLTZMAN y NEUHAUS, A Guide to the UNCITRAL Model Law in Internacional Comercial Arbitration, Kluwer (1989) (Los autores reconocen que este principio causó debate en la Comisión entre los que consideraban que debía otorgarse a los tribunales el poder de suspender la constitución del proceso arbitral mientras no se resolviera sobre el acuerdo arbitral, con el objeto de evitar arbitrajes inútiles, y entre los que consideraban que dicho poder debía ser negado a los tribunales con el objeto de evitar retardos en el proceso arbitral e intervenciones judiciales innecesarias. La opinión predominante fue que con el objeto de contribuir a una pronta resolución, ambos procesos paralelos debían ser permitidos y que, en todo caso, cualquier decisión de suspender el arbitraje correspondía al árbitro y no a los tribunales).

15 Ley 1563 de 2012. Artículo 67. Alcance de la intervención judicial. En los asuntos que se rijan por la presente sección, no podrá intervenir ninguna autoridad judicial, salvo en los casos y para los propósitos en que esta sección expresamente así lo disponga... ». Ver nota de página 13 supra.

16 Ley 1563 de 2012. Artículo 79. "FACULTAD DEL TRIBUNAL ARBITRAL PARA DECIDIR ACERCA DE SU COMPTENCIA. El tribunal es el único competente para decidir sobre su propia competencia, incluso sobre las excepciones u objeciones al arbitraje relativas a la inexistencia, nulidad, invalidez $o$ ineficacia...". Ver nota de página 13 supra. 
determinación de la competencia de los árbitros en tanto que no se haya proferido el respectivo laudo $\operatorname{arbitral}(\ldots){ }^{17}$

\section{Adicionalmente la Corte concluye}

(...) Si se aceptara que el tribunal arbitral suspendiera el proceso arbitral hasta tanto el juez se pronuncie se relegaría el arbitraje a un segundo plano, rompiendo con la voluntad de las partes que tendrían que litigar para arbitrar. ${ }^{18}$

De otra parte, todavía con relación al artículo 70 , parágrafo 2 , cabe contemplar el caso en el cual, por cuestiones de arbitrabilidad del litigio, el juez local sea el único habilitado legalmente para pronunciarse, lo cual no impediría al árbitro tomar decisiones sobre cuestiones que no son de la competencia exclusiva de la jurisdicción nacional. De cualquiera de los puntos de vista se puede concluir que la disposición, más allá de poner trabas al arbitraje, en realidad lo que hace es fortalecer la eficacia del proceso arbitral, dándole las herramientas a los árbitros para seguir conociendo del fondo del asunto.

En Latinoamérica se han tomado distintas posiciones con relación al artículo 8 de la Ley Modelo. Algunos países como Bolivia, Chile, Guatemala, Honduras, Paraguay, Argentina, Uruguay, Colombia y Perú han adoptado tanto el principio del efecto negativo y la prohibición de pronunciamiento de oficio del juez, como la facultad del árbitro de seguir conociendo del caso aun si el juez local no ha tomado todavía decisión alguna. La Ley en Ecuador no dejó clara la posibilidad al árbitro de continuar el proceso arbitral. Países como Panamá impusieron la obligación de oficio al juez de reenviar a las partes ante un tribunal arbitral, lo cual sería una posición aún más a favor del arbitraje que las otras legislaciones ${ }^{19}$.

A partir de estas consideraciones podríamos concluir que, según la ley de 2012, confrontados a una demanda simultánea, el proceso arbitral

17 Corte Constitucional. Sentencia T- 288/2013.

18 Ibid.

19 CONEJERO ROOS, Cristian. "La influencia de la ley modelo de la CNUDMI sobre arbitraje comercial internacional en américa latina: un análisis comparativo". Revista Chilena de Derecho, vol.

32, núm. 1, enero-abril, 2005, pp. 89-138, Pontificia Universidad Católica de Chile. Disponible en: http://www.redalyc.org/ pdf/1770/177021316005.pdf podrá continuar su curso y el riesgo de dos decisiones sobre el mismo asunto está descartado. Solo el tribunal arbitral podrá pronunciarse sobre el fondo del litigio.

Estas consideraciones están fortalecidas por el principio de competencia-competencia que estudiaremos a continuación.

\subsection{El principio de competencia-competencia}

Según el principio de competenciacompetencia, (Kompetenz-Kompetenz ${ }^{20}$ ), la decisión sobre la competencia para juzgar un litigio en un procedimiento arbitral es del tribunal arbitral mismo. Este principio se encuentra consagrado por la convención de Nueva York, en la mayor parte de legislaciones contemporáneas ${ }^{21}$ $\mathrm{y}$ reglamentos de arbitraje $\mathrm{e}^{22}$.

La competencia-competencia debe apreciarse teniendo en cuenta su efecto positivo y su efecto negativo, respecto de la competencia de las autoridades judiciales, frente a un litigio cubierto por una convención arbitral. En virtud del efecto positivo se permite a los árbitros determinar los límites de su competencia, sujetos a un posterior control del laudo por parte de las autoridades judiciales. ${ }^{23}$

Por su parte, el efecto negativo implica una limitación a la autoridad judicial para analizar la competencia arbitral.

El objetivo de la consagración del efecto negativo del principio de competenciacompetencia es limitar el uso de estrategias dilatorias y evitar que se recurra a procesos paralelos al arbitraje.

20 FOUCHARD Philippe, GAILLARD Emmanuel \& GOLDMAN Berthold. L'autonomie de l'arbitre international dans l'appréciation de sa propre compétence, en Collected Courses of the Hague Academy of International Law, Vol. 217, 1989, Parte 5 Pag 319.

21 Ver por ejemplo Arbitration Act 1996, Artículo 1465 Código de Procedimiento Civil Francés entre otros.

22 Ver por ejemplo ley modelo de la CNUDMI, nota de página 10 supra y el reglamento 2012 de la CCI, disponible en http:// www.iccwbo.org/products-and-services/arbitration-and-adr/ dispute-boards/dispute-board-rules/.

23 FOUCHARD Philippe, GAILLARD Emmanuel \& GOLDMAN. On International Commercial Arbitration" La Haya, Kluwer law international. 1999 Nota 7, página 393. 
La consagración en el sistema legal francés de este principio fue objeto de codificación desde hace muchos años. Actualmente se encuentra en el artículo 1465 del Código de Procedimiento $\mathrm{Civil}^{24}$, sin embargo, fue gracias al trabajo de los jueces que su definición y sus alcances fueron ampliamente desarrollados.

En sentencia del 14 de noviembre de 2007, SIAL c/ VINEXPO, la Corte de Casación francesa señaló que:

(...)Teniendo en cuenta los artículos 1444 y 1457 del nuevo Código de Procedimiento Civil y el principio de competencia-competencia.

Considerando que, para rechazar la solicitud de nombramiento de un árbitro, la sentencia sostiene que la presencia en los estatutos de una contradicción entre una cláusula de jurisdicción y una cláusula compromisoria constituye una seria contestación frente a la designación del árbitro;

Que el juez de apoyo no puede oponerse a la designación de un árbitro que si la cláusula compromisoria es manifiestamente nula o insuficiente para permitir la constitución de un tribunal arbitral y que le corresponde al árbitro de decidir en prioridad sobre su propia competencia, el juez de apoyo, al haber dictado una decisión violo los textos y el principio mencionado ${ }^{25}$. (Traducción libre)

En el derecho colombiano la consagración del principio de competencia- competencia es más reciente, de hecho, es bajo el imperio del decreto

24 Código de procedimiento civil francés. Artículo 1465 :

"Le tribunal arbitral est seul compétent pour statuer sur les contestations relatives à son pouvoir juridictionnel ». Disponible en http://www.legifrance.gouv fr/affichCodeArticle.do:jsessio nid=7A6F1BF32FEF526E5D7FEC2362AC2F4F.tpdjo03v_2?idA rticle $=$ LEGIARTI000023450814\& cidTexte $=$ LEGITEXT0000060 $70716 \&$ date Texte $=20130317 \&$ categorieLien $=i d \&$ oldAction $=$ Traducción ver nota de pagina 14.

25 Corte de Casación. Primera sala civil. 14 de noviembre de $2007 n^{\circ} 06 / 21.629$.

"Vu les articles 1444 et 1457 du nouveau code de procédure civile et le principe de compétence-compétence,

Attendu que, pour rejeter la demande de désignation d'un arbitre, l'arrêt retient que la présence, dans les statuts, d'une contradiction entre une clause attributive de juridiction et une clause compromissoire constitue une contestation sérieuse s'opposant à la désignation d'un arbitre;

En statuant ainsi alors que le juge d'appui ne peut refuser de désigner un arbitre que si la clause est manifestement nulle ou insuffisante pour permettre la constitution d'un tribunal arbitral et qu'il appartient à l'arbitre de se prononcer, par priorité, sur sa propre compétence, le juge d'appui, statuant en référé, a violé les textes et le principe susvisés. »
147 de 1998 cuando se incluyó inicialmente, de manera modesta, en el panorama jurídico colombiano. Por su parte la Corte Constitucional, mediante la sentencia SU- 174 de 2007, se refirió a este principio en el ámbito internacional y concluyó que estaba vigente en la práctica del arbitraje en Colombia.

Posteriormente la Ley 1563 del 2012 lo desarrolla de una manera más amplia en su artículo 79 que otorga al tribunal arbitral la facultad para decidir sobre su propia competencia $^{26}$. La sala séptima de revisión de tutelas de la Corte Constitucional determinó en sentencia T-288 del 20 de mayo del $2013^{27}$ los alcances del principio en los siguientes términos:

(...) De la anterior disposición normativa se destaca, entre otros, que de conformidad al principio de Kompetenz-Kompetenz, el tribunal arbitral es el único competente para establecer su competencia excluyéndose cualquier injerencia judicial en la materia (...).

En este sentido la jurisprudencia de los dos países expresa de manera similar los alcances y el objeto del principio de competencia-competencia.

\section{SOBRE LAS MEDIDAS DE INSTRUCCIÓN, MEDIDAS PREVISORAS Y MEDIDAS CONSERVATORIAS}

A pesar del principio de la autonomía del procedimiento arbitral ${ }^{28}$, el decreto y ejecución de las medidas de instrucción y cautelares exigen en ocasiones la interacción entre la justicia privada y el Estado.

Analizaremos en una primera parte, en los dos sistemas judiciales objeto de nuestro estudio,

26 Ley 1563 de 2012. Artículo 79. « Facultad del tribunal para decidir acerca de su competencia. El Tribunal arbitral es el único competente para decidir sobre su propia competencia, incluso sobre las excepciones u objeciones relativas a la inexistencia, nulidad, anulabilidad, invalidez o ineficacia del acuerdo de arbitraje... "Ver nota de página 13 supra.

27 Ver nota de página número 21 supra.

28 Ver entre otros los comentarios de FOUCHARD, Philippe de la Sentencia de la Corte de Apelaciones de Paris de 18 de noviembre de 1987. Chambre arbitrale de Paris v. République de Guinée, 1988. REV. ARB. 657. Adicionalmente el comentario del mismo autor de la sentencia del Tribunal de "Grande instance 》 de febrero 15 de 1995, Industrial export v K. REV. ARB. 503 de 1995 y GAILLARD, Emmanuel, Les manœuvres dilatoires des parties et des arbitres dans l'arbitrage commercial international, 1990 REV. ARB. Especialmente en Pp. 761 y siguientes. 
los principios rectores de la relación entre los jueces estatales y los tribunales arbitrales en lo relacionado con las medidas cautelares (2.1), y en una segunda parte los diferentes tipos de medidas que pueden ser decretadas antes y durante el procedimiento arbitral (2.2).

\subsection{La competencia del Tribunal arbitral y de los jueces ordinarios}

En materia de arbitraje internacional el principio de competencia concurrente entre los tribunales arbitrales y los jueces estatales para decretar medidas cautelares, es ampliamente reconocido ${ }^{29}$. Sin embargo, este principio presenta ciertos límites que tienen relación con la libertad contractual expresada en el convenio arbitral.

Los jueces estatales y los tribunales arbitrales se asocian con un objetivo preciso: facilitar el trabajo del tribunal arbitral. Los jueces no se pronuncian sobre el fondo del asunto sino que intervienen en un rol secundario. ${ }^{30} \mathrm{Si}$ el juez ordinario mantiene cierta competencia (2.1.1), esta competencia no equivale a la que se desprende del convenio arbitral para los árbitros (2.1.2).

\subsubsection{La competencia de los jueces ordinarios}

El principio de la competencia concurrente implica que la existencia de un convenio arbitral no imposibilita a las partes de acudir a la justicia ordinaria para solicitar el decreto de medidas cautelares en situaciones de urgencia.

En derecho francés el artículo $1449^{31}$ del Código de procedimiento Civil retomó las

29 Varios ejemplos pueden citarse, particularmente en las sentencias de la Corte de justicia Europea, por ejemplo la sentencia C-391/95 de 17 de noviembre de 1998, sobre la interpretación del Convenio de Bruselas en lo referido al convenio arbitral y las medidas cautelares. En http://curia.europa.eu/ juris/document/document.jsf?text $=\&$ docid $=44211 \&$ pageIndex= $0 \&$ doclang $=E S \&$ mode $=l$ st $\&$ dir $=\&$ occ $=$ first $\&$ part $=1 \&$ cid $=405200$

30 VEEDER, VV, L'affaire du tunnel sous la manche et les mesures conservatoires, 1993 REV. ARB. 705.

31 Código de procedimiento civil Frances. Art 1449

"... L'existence d'une convention d'arbitrage ne fait pas obstacle, tant que le tribunal arbitral n'est pas constitué, à ce qu'une partie saisisse une juridiction de l'Etat aux fins d'obtenir une mesure d'instruction ou une mesure provisoire ou conservatoire. Sous réserve des dispositions régissant les saisies conservatoires et les sûretés judiciaires, la demande est portée devant le président du tribunal de grande instance ou de commerce, qui statue sur les mesures d'instruction dans les conditions prévues soluciones jurisprudenciales en la materia y permite a las partes solicitar ante los tribunales estatales la práctica de medidas cautelares, antes de la constitución del Tribunal Arbitral.

Según una doctrina minoritaria también se podría solicitar el decreto de medidas cautelares después de la constitución del tribunal arbitral ${ }^{32}$, considerando que

La posibilidad de recurrir al juez, a pesar de que el tribunal arbitral sea constituido debe ser admitida en principio, porque no se puede excluir de encontrar ciertos casos en los que a pesar que el tribunal arbitral, a pesar de haber sido instaurado y a pesar de los poderes del árbitro, no estará en posición de ordenar eficazmente la medida necesaria solicitada. ${ }^{33}$ (Traducción libre).

El derecho francés también exige que la parte demandante demuestre la "urgencia" de las medidas en el caso de que las circunstancias no permitan que se espere hasta la constitución del tribunal arbitral. Adicionalmente, el artículo $145^{34}$ del Código de Procedimiento Civil, permite a las partes de solicitar a la justicia ordinaria una medida cautelar para obtener pruebas de las que pudieran depender la solución del litigio.

En el derecho colombiano la Ley 1563 de 2012 , artículo $71^{35}$, sobre el arbitraje internacional,

$\overline{a ̀ ~ l ' a r t i c l e ~} 145$ et, en cas d'urgence, sur les mesures provisoires ou conservatoires sollicitées par les parties à la convention d'arbitrage.. ".Disponible en http://www.legifrance.gouv.fr/ affichCodeArticle.do;jsessionid=7A6F1BF32FEF526E5D7FEC23 62AC2F4F.tpdjo03v_2?idArticle $=$ LEGIARTI000023450940\&cidT exte $=$ LEGITEXT000006070716\&dateTexte $=20130317 \&$ categori eLien=id\&oldAction=. Traducción ver nota de página 14 supra.

32 JARRONSON Ch., PELLERIN, J. Le droit Français de l'arbitrage après le décret du 13 janvier 2011. REV. ARB. 2011. 5 especial, pag 16.

33 Respecto al tema, MM. Charles Jarrosson et Jacques Pellerin considéran que "il nous semble que la possibilité de recourir en référé au juge étatique lorsque le tribunal est constitué doit être admise dans son principe, car on ne peut exclure de rencontrer des hypothèses dans lesquels le tribunal arbitral, même saisi et même muni des pouvoirs qui sont les siens, ne sera pas en position d'ordonner efficacement la mesure nécessaire souhaitée. Ver nota de página supra 32.

34 Codigo de procedimiento civil Frances Art 145.

S'il existe un motif légitime de conserver ou d'établir avant tout procès la preuve de faits dont pourrait dépendre la solution d'un litige, les mesures d'instruction légalement admissibles peuvent être ordonnées à la demande de tout intéressé, sur requête ou en référé... " Disponible en http://www.legifrance.gouv.fr/ affichCodeArticle.do?idArticle $=$ LEGIARTI000006410268\&cidT exte=LEGITEXT000006070716. Traducción ver nota de página 14 supra.

35 Ley 1563 de 2012 Artículo 71. Acuerdo de arbitraje y decreto 
faculta a las partes para solicitar a una autoridad judicial medidas cautelares antes o después de la constitución del tribunal arbitral.

Para la redacción de este artículo el legislador Colombiano se inspiró en el reglamento de arbitraje de la $\mathrm{CCI}^{36}$ que, en su artículo $28^{37}$ numeral 2, permite a las partes acudir a instancias judiciales para el decreto de medidas cautelares, antes o después de la constitución del tribunal arbitral.

Mientras el derecho francés limita al máximo la intervención del juez estatal en el transcurso del procedimiento arbitral, el derecho colombiano es más acogedor y confortable con la idea de concurrencia de jurisdicción. En el caso de medidas cautelares este enfoque podría favorecer al arbitraje internacional, garantizándole una mejor eficacia en lo que se refiere a medidas cautelares.

Sin embargo, es necesario interrogarse sobre el hecho de si en el derecho Colombiano la intervención del juez no es excesiva. ¿Qué pasaría, por ejemplo, si ante la negativa de un árbitro de proceder a una medida cautelar en el transcurso de un proceso arbitral, las partes acuden al juez ordinario para solicitarla y este la otorga? Entonces ¿no existe el riesgo de que el árbitro pierda autoridad/legitimidad en su acción puesto que su decisión podría ser cuestionada por una instancia judicial? No estando confrontados a una situación fáctica concreta de este tipo, habrá que esperar la respuesta de la jurisprudencia en la materia. Según lo decidan los jueces, el arbitraje será un medio de resolución de conflictos

de medidas cautelares por una autoridad judicial. Cualquiera de las partes, con anterioridad a las actuaciones arbitrales o durante el transcurso de las mismas, podrá solicitar de una autoridad judicial la adopción de medidas cautelares y esta podrá decretarlas, sin que por ello se entienda que ha renunciado al acuerdo de arbitraje..." Ver nota de página 13 supra.

36 Sigla de la Cámara de Comercio Internacional

37 Ley 1563 de 2012 ARTÍCULO 28. "Medidas cautelares y provisionales..." "... Antes de la entrega del expediente al tribunal arbitral, y en circunstancias apropiadas aun después, las partes podrán solicitar a cualquier autoridad judicial competente la adopción de medidas provisionales o cautelares. La solicitud que una parte haga a una autoridad judicial con el fin de obtener tales medidas o la ejecución de medidas similares ordenadas por un tribunal arbitral no contraviene al acuerdo de arbitraje ni constituye una renuncia a éste y no afecta los poderes del tribunal arbitral al respecto. Dicha solicitud, así como cualquier medida adoptada por la autoridad judicial, debe ser notificada sin dilación a la Secretaría. Esta última informará de ello al tribunal arbitral..." Ver nota de página 13 supra. independiente y respetado o, al contrario, un modo privado de justicia, visto como concurrente de la jurisdicción de los tribunales estatales.

\subsubsection{La no renuncia al convenio de arbitraje}

A pesar de que las partes acudan a las autoridades judiciales no existe una renuncia a la convención arbitral. La jurisprudencia y la doctrina francesa son unánimes sobre el hecho de que el decreto de medidas cautelares no es equivalente a una renuncia a la convención $\operatorname{arbitral}^{38}$, el poder para dirimir el fondo del conflicto quedaría todavía en cabeza del tribunal arbitral ${ }^{39}$. Esta misma aclaración es hecha en la disposición citada del derecho Colombiano.

La compatibilidad entre las medidas cautelares y la convención arbitral también es reconocida, entre otras, por la reglas de la CCI, las reglas de la CNUDMI, las reglas de arbitraje internacional AAA (American Arbitration Association) y las reglas de la Cámara de Comercio de Estocolmo.

\subsubsection{La competencia de los árbitros}

En el derecho Colombiano la capacidad de los árbitros para decretar medidas cautelares fue objeto de la sentencia de constitucionalidad C-431 del 28 de septiembre de 1995 en los siguientes términos:

Dada la facultad constitucional en cabeza del legislador para limitar o ampliar el ámbito de competencia de los árbitros, señalando para el efecto el procedimiento y requisitos que se exigen para el efecto. Si el juez en su tarea de administrar justicia goza de la facultad de decretar medidas cautelares, lo puede hacer también el árbitro al ser investido del poder de administrar justicia. Al decretar el árbitro medidas cautelares, lo único que está haciendo es uso del poder de coerción

38 Corte de Apelaciones de Paris, 6 febrero de 1991, Groupe Courtand c/ Société Beam Morin, inédito.

39 Corte de Apelaciones de Paris, 19 de diciembre de 1982. REV $A R B, 1983.181$, nota de MOREAU B ; Corte de Casación. Sala primera civil, 20 de marzo de 1989, REV ARB., 1989. 494, 3 nota de COUCHEZ G., Corte de Casación. Sala Civil 2, 29 de noviembre de 1989 y 6 de marzo de 1990. 633, nota GAUDEMENT-TALLON GH. Corte de Apelaciones de París, 30 de enero 1992 y Corte de Apelaciones de Versalles, 22 de mayo de 1992, REV ARB 1992.666, obs. MOIRTRY J-H. 
con miras a lograr la efectividad de su decisión; al hacerlo, en ningún momento está usurpando una competencia que no le corresponda en forma privativa y excluyente a la justicia ordinaria (...)

(...) En virtud a lo anterior, estima la Corte Constitucional que al ser investidos -transitoriamente- los árbitros de la función de administrar justicia, es lógico, consecuente y ajustado al ordenamiento superior y legal vigente, que los árbitros dentro del trámite y curso del proceso arbitral -a petición de cualquiera de las partes-, puedan decretar las medidas cautelares, particularmente cuando su finalidad no sólo es la garantía del equilibrio entre las partes en el transcurso y desarrollo del proceso, sino también evitar que se hagan nugatorias las determinaciones que se adopten, por lo que las normas que se examinan se encuentran conformes con la Carta Política. ${ }^{40}$

De acuerdo con esta jurisprudencia, el legislador en el año 2012 consagró la capacidad de dictar medidas cautelares en el artículo $80^{41}$ y siguientes de la Ley 1563 respecto del arbitraje internacional, incorporando así parcialmente el artículo $17^{42}$ de la ley modelo CNUDMI en su versión de 2006.

Por su parte, el artículo $1468^{43}$ del Código de Procedimiento Civil francés, faculta al árbitro

40 Corte Constitucional, Sentencia de Constitucionalidad No. C-431/95 del 28 de septiembre de 1998. Disponible en http://www.ciac-iacac.org/documentos/2007_3_31_14_30_7_ Sentencia_431_1995.pdf

41 Ley 1563 de 2012 “...Artículo 80. Facultad del tribunal arbitral para decretar medidas cautelares: Salvo acuerdo en contrario de las partes, el tribunal arbitral podrá, a instancia de cualquiera de ellas, decretar medidas cautelares.

Por medida cautelar se entenderá toda medida temporal, decretada en forma o no de laudo, por la que, en cualquier momento previo a la emisión del laudo por el que se dirima definitivamente la controversia, el tribunal arbitral ordene a una de las partes que:

a) Mantenga o restablezca el status quo en espera de que se dirima la controversia;

b) Adopte medidas para impedir algún daño presente o inminente, o el entorpecimiento del procedimiento arbitral, o que se abstenga de realizar actos que probablemente ocasionarían dicho daño o entorpecimiento al procedimiento arbitral;

c) Proporcione algún medio para preservar bienes cuya conservación permita ejecutar el o los laudos; o

d) Preserve elementos de prueba que pudieran ser pertinentes y relevantes para resolver la controversia...

Ver nota de página 13 supra.

42 Ley Modelo de la CNUDMI sobre Arbitraje Comercial Internacional 1985 con las enmiendas aprobadas en 2006, disponible en : http://www.uncitral.org/pdf/spanish/texts/ arbitration/ml-arb/07-87001_Ebook.pdf.

43 Código de procedimiento Civil francés articulo 1468.

"Le tribunal arbitral peut ordonner aux parties, dans les para decretar medidas cautelares provisionales o de protección so pena de multa en caso de no cumplimiento, aunque no para ordenar medidas relacionadas con el embargo o secuestro de bienes o el establecimiento de garantías judiciales que continúan siendo una facultad exclusiva de los jueces ordinarios ${ }^{44}$.

Es evidente que frente al derecho francés, la legislación colombiana otorga facultades completas al árbitro para declarar cualquier medida cautelar que permita el desarrollo del proceso o la adecuada ejecución del laudo.

\subsubsection{Los límites de la competencia concurrente}

El principio de competencia concurrente de los jueces estatales y los árbitros para decretar medidas cautelares está limitado por dos circunstancias, el acuerdo de las partes y los temas en los cuales los jueces ordinarios cuentan con una competencia exclusiva.

\subsubsection{El acuerdo entre las partes}

Las partes pueden renunciar mediante el convenio arbitral al decreto de medidas cautelares por parte del árbitro; frente a este aspecto las dos legislaciones son similares. La posibilidad de las partes de renunciar al decreto de medidas cautelares en la cláusula compromisoria en Colombia, artículo 80 de la Ley 1563, se adoptó siguiendo el artículo 17 de la Ley Modelo. Sin

conditions qu'il détermine et au besoin à peine d'astreinte, toute mesure conservatoire ou provisoire qu'il juge opportune. Toutefois, la juridiction de l'Etat est seule compétente pour ordonner des saisies conservatoires et sûretés judiciaires. Le tribunal arbitral peut modifier ou compléter la mesure provisoire ou conservatoire qu'il a ordonnés... Disponible en http://www. legifrance.gouv.fr/affichCodeArticle.do;jsessionid $=7 A 6 F 1 B F 32 F$ EF526E5D7FEC2362AC2F4F.tpdjo03v_2?idArticle = LEGIARTIO0 $0023450801 \&$ cidTexte $=$ LEGITEXT000006070716\&dateTexte $=2$ 0130317\&categorieLien=id\&oldAction=. Traducción ver nota de página 14 supra.

44 El artículo 1468 del Código de Procedimiento Civil Francés ha reconocido al árbitro el poder de ordenar, eventualmente bajo pena de multa, medidas cautelares provisionales, pero ciertas medidas son competencia exclusiva de los jueces estatales. Será el presidente del tribunal de Grande Instance o en su defecto el de comercio que decidirá sobre las solicitudes de medidas cautelares. En este sentido encontramos las jurisprudencias: Corte de apelaciones de Paris 7 octubre de 2004, JCP G 2005. II. 10071, nota de JACQUET J.M, igualmente, Corte de apelaciones de Rennes, 26 de octubre de 1984, REV. ARB. 1985. Pagina 439. 
embargo, el principio general consiste en la existencia de este poder por parte de los árbitros, negar tal poder, aun por medio de la cláusula, resultaría peligroso para las mismas partes en la disputa, debido a que se traduciría en una mayor intervención del juez local, lo cual se intenta evitar en el arbitraje internacional, y en procesos arbitrales más demorados, limitando el poder del tribunal arbitral. A pesar de esto se deja la libertad a las partes de renunciar al decreto de medidas en el caso de que consideren que no son necesarias o que pueden entorpecer la toma de decisión del tribunal.

La legislación Francesa más reciente adopta una jurisprudencia antigua, proveniente de la Corte de Casación del 18 de noviembre de 1986, "Atlantic Triton". En esta sentencia el juez supremo francés declaró que "[e]l poder de los tribunales para ordenar medidas provisionales... Sólo pueden ser excluidos por un acuerdo explícito entre las partes por un acuerdo implícito resultante de la adopción de normas de arbitraje que contengan tal exclusión..." ${ }^{45}$

\section{EL JUEZ DE APOYO}

Otra de las manifestaciones de la colaboración entre el juez y el árbitro se aprecia a través del denominado juez de apoyo. Inspirada en el derecho suizo del arbitraje, la función del juez como apoyo en el arbitraje ha existido por un largo tiempo en Francia y corresponde a una singularización de la función del juez "soporte del proceso arbitral”, función diferente de la del juez controlador o sancionador.

La función del juez de apoyo en Francia recae en el presidente del "Tribunal de Grande Instance" o, si las partes lo acuerdan, en el presidente del Tribunal de Comercio, quien tiene una misión de asistencia y cooperación en el proceso arbitral siempre y cuando exista una conexión con Francia ${ }^{46}$.

45 COUCHEZ G., Compare, as regards " référé provision 》, Corte de Casacion. Sala 2 Civil. , Marzo 20 de 1989. Danel v Sotiat Informatique, 1989 Rev. Arb. 494.

46 Ver jurisprudencia Corte de Casación. Primera sala civil, 1 de febrero de 2007, BICC N 663,15 junio de 2007. «Dès lors que l'absence de volonté des parties de recourir à l'arbitrage n'est pas démontrée, la clause compromissoire désignant deux institutions d'arbitrage n'est pas manifestement inapplicable et les difficultés de constitution du tribunal arbitral relèvent, pour un arbitrage international se déroulant en France, du président du tribunal de
Su participación en el proceso arbitral es subsidiaria y está limitada a los momentos en los cuales existan dificultades en la instancia arbitral, sea para la constitución del tribunal o en eventos precisos como en los casos de recusación de los árbitros, la renuncia, el deceso del árbitro durante el proceso arbitral o el cambio de los árbitros por razones diversas.

Por su parte, en Colombia la ley 1563 de 2012, a pesar de no adoptar la denominación exacta de juez de apoyo, también prevé la intervención de la autoridad judicial como soporte al proceso arbitral. Esta función, igualmente subsidiaria, está consagrada en los artículos 73 numerales 5 y 6, 76 numeral 2, 77 numeral 1 y el artículo 100, los cuales consagran sus funciones de manera similar al del denominado juez de apoyo en derecho francés.

La competencia se encuentra en cabeza del juez civil del circuito y cuando se trate de tribunales arbitrales en los que sea parte una entidad pública colombiana o quien ejerza funciones administrativas colombianas, el juez administrativo. Sin embargo, una particularidad contenida en el artículo 100 de la ley de 2012, permite que cualquier autoridad judicial de cualquier país pueda venir en ayuda del proceso arbitral para la práctica de pruebas en su territorio. Esto bajo la condición que el tribunal arbitral lo autorice.

Analizaremos sucesivamente las dificultades en el procedimiento que pueden hacer necesaria la intervención del juez de apoyo: al inicio del procedimiento cuando las partes no logran un acuerdo para el nombramiento de los árbitros, (3.1), en los casos de recusación o de renuncia del árbitro (3.2), o cuando por otras razones el cambio de árbitro sea indispensable (3.3).

\subsection{La Constitución del Tribunal Arbitral}

Cuando las partes no logran ponerse de acuerdo sobre la constitución del tribunal arbitral, o en los casos de los arbitrajes ad-hoc la parte la más diligente puede acudir al juez de apoyo.

grande instance de Paris, juge d'appui » 
La intervención del juez de apoyo francés en la constitución del Tribunal Arbitral se encuentra consagrada en los artículos 1451, 1452, 1453 y 1454 del Código de procedimiento civil.

Art. 1452. A falta de acuerdo de las partes sobre el modo de designación del árbitro o de los árbitros, se procederá de la siguiente forma:

1ํㅡㄹ arbitrajes con un árbitro único, si las partes no pueden llegar a un acuerdo sobre el árbitro, éste será designado por la persona encargada de administrar el arbitraje o en su defecto, por el juez de apoyo;

2o En arbitrajes con tres árbitros, cada parte escogerá un árbitro y los dos árbitros así escogidos designarán el tercero; si una parte no designa un árbitro en un plazo de un mes contado a partir del momento en que la otra parte le requiera para ello, o si los dos árbitros no llegan a un acuerdo sobre el tercero en un plazo de un mes contado desde la aceptación de su designación, la persona encargada de administrar el arbitraje o en su defecto, el juez de apoyo, procederá a tal designación ${ }^{47}$.

Por su parte la Ley de 2012 incorpora la intervención del juez de apoyo en la constitución del tribunal de la siguiente manera ${ }^{48}$ :

Artículo 73 Nombramiento de los árbitros. En el nombramiento de árbitros en el arbitraje internacional:
.. 4. Las partes podrán acordar libremente el procedimiento para la designación del árbitro o los árbitros.

\section{A falta de acuerdo:}

a) En el arbitraje con árbitro único, si las partes no consiguen ponerse de acuerdo sobre la designación del árbitro dentro de los treinta (30) días contados a partir de la solicitud de una de ellas, la autoridad judicial procederá al nombramiento a instancia de cualquiera de las partes;

b) En el arbitraje con tres árbitros, cada parte nombrará un árbitro y los dos árbitros así designados nombrarán al tercero; si una parte no nombra al árbitro dentro de los treinta (30) días siguientes al recibo de requerimiento de la otra parte para que lo haga, o si los dos árbitros no consiguen ponerse de acuerdo sobre el tercero dentro de los treinta (30) días contados desde la comunicación de su nombramiento, la designación será hecha por la autoridad judicial, a petición de cualquiera de ellas.

6. Cuando en un trámite de nombramiento convenido por las partes:

a) Una parte no actúe conforme a lo estipulado en dicho trámite; o

b) Las partes, o los árbitros, no puedan llegar a acuerdo conforme al mencionado trámite; o

c) Un tercero, incluida una institución, no cumpla la función correspondiente, cualquiera de las partes podrá solicitar a la autoridad judicial que nombre el árbitro o adopte la medida necesaria, a menos que en el acuerdo sobre el trámite de nombramiento se prevean otros medios para conseguirlo(...)

En los dos sistemas el carácter subsidiario de la intervención del juez de apoyo está específicamente definido: es solo en caso en que las partes no se hayan puesto de acuerdo en la aplicación de un reglamento institucional de arbitraje, o si la institución no cuenta en su reglamento con un procedimiento para remediar la situación, o que las partes no logran ponerse de acuerdo en la constitución del tribunal arbitral que, a solicitud de una de las partes, el juez de apoyo intervendrá. 
En el derecho francés, una vez ha sido interpuesta la solicitud para la intervención del juez de apoyo, su competencia es de orden público y las partes no podrán escoger otro juez que no sea el juez de apoyo. ${ }^{49}$ El artículo 1452 contempla el caso de un convenio arbitral que prevea uno o tres árbitros. Sin embargo, en caso de que la cláusula compromisoria no prevea el número de árbitros, por aplicación del artículo 1454 del CPC, será la institución encargada de organizar el arbitraje, o el juez de apoyo, quien procederá a determinar el número.

Esta solución también se aplica respecto del arbitraje "Multipartes". El nuevo artículo $1453^{50}$ del código de procedimiento civil francés, adoptó la solución consagrada en la sentencia Dutco ${ }^{51}$ de 1992, en donde los tribunales franceses acogieron la solución propuesta por el reglamento de arbitraje de la CCI, que en su artículo $12.4^{52}$, establece que si las partes no llegan a un acuerdo respecto de la designación del árbitro, o de varios árbitros, estos deberán ser designados por el centro de arbitraje o el juez de apoyo. Eso se hizo para evitar las situaciones en que más de dos partes al arbitraje pretenden escoger un árbitro, lo cual podría generar problemas en la constitución del tribunal, por eso se contemplan en esos casos, a falta de acuerdo entre las distintas partes, que la autoridad encargada de la designación los nombre a todos.

En el derecho colombiano la regla general sigue siendo la de la libertad de las partes en la

\section{Ver nota de página 32 supra.}

50 Código de procedimiento civil francés Articulo 1453. «Lorsque le litige oppose plus de deux parties et que celles-ci ne s'accordent pas sur les modalités de constitution du tribunal arbitral, la personne chargée d'organiser l'arbitrage ou, à défaut, le juge d'appui, désigne le ou les arbitres ». Disponible en http://www. legifrance.gouv.fr/affichCodeArticle.do;jsessionid=001EA7D80D 90C779215F5E1A5CDE2283.tpdjo05v_3?idArticle =LEGIARTIO0 $0023450922 \&$ cidTexte $=$ LEGITEXT000006070716\&dateTexte $=2$ 0130311\&categorieLien=id\&oldAction=. Traducción ver nota de página 14 supra.

51 Casación civil 1, 7 de enero de 1992, REV.ARB., 1992 471, nota BELLET, P. ; JDI, 1992. 707. Nota JARRONSON, Ch.

52 Ver reglamento de Arbitraje de la Cámara de Comercio Internacional Vigente a partir del $1^{\circ}$ de enero de 2012. ".. Artículo 12. Constitución del tribunal arbitral...” “... 4. Cuando las partes hayan acordado que la controversia deberá ser resuelta por tres árbitros, cada parte, en la Solicitud y en la Contestación, respectivamente, deberá designar un árbitro para su confirmación. Si una parte se abstiene de designar árbitro, el nombramiento será hecho por la Corte..." Disponible en http:// $w w w . g 00 g l e . f r / \# f p=f 6670336 a 8 f 8 c 7 a \& q=$ reglamento $+c c i+a r b$ traje+2012 escogencia del tribunal arbitral y la intervención excepcional del juez de apoyo. Si la cláusula compromisoria no dice nada sobre la constitución del tribunal pero indica que el arbitraje es institucional, se entiende que se aplicarán las reglas de constitución del tribunal arbitral consagradas en el reglamento de la institución arbitral escogida por las partes. Si las partes no se ponen de acuerdo o la institución arbitral no contiene reglas sobre la constitución del tribunal, o simplemente no cumple su misión, es el juez de apoyo quien interviene para subsanar el tropiezo. Además de esto el artículo 73 de la Ley 1563 permite la intervención del juez de apoyo, solo si el trámite de nombramiento no contiene otro medio de solucionar el impase.

Adicionalmente, la Ley 1563 en el artículo 73 (7) prevé otras particularidades novedosas del sistema. En caso de intervención del juez, éste debe asegurarse de que los árbitros que serán designados son independiente e imparciales y tener en cuenta las calidades especiales que las partes hayan acordado que los árbitros deben cumplir, por ejemplo respecto del área de especialidad, profesión, etc.

Finalmente, en materia internacional, el juez debe sopesar la conveniencia de proceder a la designación de árbitros de nacionalidad distinta a la de las partes. En efecto, la intervención de árbitros de nacionalidad diferente puede constituir un elemento de garantía para las partes de que existirá neutralidad por parte del tribunal arbitral y también de que, en determinados casos, solo un árbitro extranjero podría entender íntegramente el querer de las partes.

Si el juez de apoyo observa que una parte es colombiana y la otra es española, por ejemplo, y se percata de que un tribunal compuesto solo por árbitros colombianos no atendería de la mejor manera los requerimientos de las partes, puede proceder a la designación de un árbitro colombiano, uno español y, ¿por qué no?, un tercero de otra nacionalidad que permita creer en la transparencia del sistema. También existe el caso en que las dos partes sean extranjeras y elijan alguna ciudad colombiana como sede del arbitraje; si por ejemplo las dos partes son de la cultura del common law, mal haría el juez de apoyo en designar un tribunal compuesto solo por abogados del civil law, salvo que esa fuera la voluntad de las partes. 
Una vez el tribunal arbitral ha sido constituido, con o sin la intervención del juez de apoyo al inicio del procedimiento arbitral, otras situaciones pueden necesitar de su intervención, como el procedimiento de recusación que estudiaremos a continuación:

\subsection{La recusación del árbitro}

La recusación es un procedimiento mediante el cual una de las partes solicita que el árbitro sea sancionado a causa de una incertitud grave sobre su imparcialidad ${ }^{53}$, también puede ser considerado como un mecanismo de prevención para que el árbitro se separe del tribunal y de esta manera salvaguardar el procedimiento arbitral.

La relación existente entre los árbitros y las partes en el procedimiento debe ser transparente, esto se reflejará en el fondo del litigio, más aun si se tiene en cuenta que los poderes otorgados a los árbitros para dirimir el litigio son los mismos de un juez, aun si se trata de una misión transitoria.

Las instituciones de arbitraje internacional imponen en sus reglamentos procedimientos de control sobre la imparcialidad de los árbitros, la $\mathrm{CCI}^{54}$, por ejemplo, entrega a los árbitros un

53 DE BOISSEISON, M. "Le droit français de l'arbitrage interne et international. GLN Joly Edition. Pag 777 y 778.

54 El reglamento de la CCI 2012 sobre el arbitraje establece en su artículo 11 la obligación de revelación e imparcialidad en los siguientes términos:

Article 11: General Provisions

1) Every arbitrator must be and remain impartial and independent of the parties involved in the arbitration.

2) Before appointment or confirmation, a prospective arbitrator shall sign a statement of acceptance, availability, impartiality and independence. The prospective arbitrator shall disclose in writing to the Secretariat any facts or circumstances which might be of such a nature as to call into question the arbitrator's independence in the eyes of the parties, as well as any circumstances that could give rise to reasonable doubts as to the arbitrator's impartiality. The Secretariat shall provide such information to the parties in writing and fix a time limit for any comments from them.

3) An arbitrator shall immediately disclose in writing to the Secretariat and to the parties any facts or circumstances of a similar nature to those referred to in Article 11(2) concerning the arbitrator's impartiality or independence which may arise during the arbitration.

4) The decisions of the Court as to the appointment, confirmation, challenge or replacement of an arbitrator shall be final, and the reasons for such decisions shall not be communicated.

5) By accepting to serve, arbitrators undertake to carry out their responsibilities in accordance with the Rules.

6) Insofar as the parties have not provided otherwise, the arbitral tribunal shall be constituted in accordance with the provisions of Articles 12 and 13.

Disponible en : http://www.iccwbo.org/Products-andServices/Arbitration-and-ADR/Arbitration/ICC-Rules-of- cuestionario en el cual deben revelar la relación que puedan tener con las partes. El reglamento de la AFA prevé asimismo la obligación del árbitro de realizar una declaración de independencia ${ }^{55}$.

Pero además de la independencia, ciertas legislaciones en arbitraje internacional incluyen otras causales de recusación, como la suiza que permite recusar un árbitro por no cumplir con las competencias requeridas por las partes ${ }^{56}$. La legislación colombiana adopta también esta causa adicional de recusación.

En derecho francés la recusación está codificada en el artículo 1456 del código de procedimiento civil.

(...) El tribunal arbitral se considerará constituido cuando el árbitro o los árbitros acepten la misión que les ha sido confiada. En ese momento aboca el conocimiento de la controversia. Antes de aceptar su misión, el árbitro deberá revelar cualquier circunstancia que pudiera afectar su independencia o imparcialidad. Tiene también la obligación de revelar sin dilación, cualquier circunstancia de igual naturaleza que pudiera surgir después de la aceptación de su misión.

En caso de controversia sobre la permanencia del árbitro, esta será resuelta por la persona encargada de administrar el arbitraje o en su defecto, por el juez de apoyo, a quien deberá someterse la

Arbitration/\#article_5

55 El reglamento de arbitraje de la AFA prevé la obligación de revelación en los siguientes términos:

Article 4. L'arbitre-indépendance et obligations.

Article 4. $\$ 1$

Tout arbitre désigné par une partie ou par le Comité d'arbitrage remet à celui-ci, en acceptant ses fonctions, une déclaration d'indépendance. Cette déclaration doit signaler toutes circonstances que pourraient être de nature, aux jeux des parties à affecter cette indépendance.

Article 4.\$2.

Dans ce dernier cas, le Comité d'arbitrage communique aux parties les circonstances signal »s, pour recueillir leurs observations éventuelles, avant de prendre la décision qui lui incombe de nommer ou non l'intéressé. Article $4 . \$ 3$

Tout arbitre s'engage à exécuter conformément au Règlement d'arbitrage et avec diligence la mission qu'il a acceptée.

56 Article 180. “... Récusation des arbitres.

Un arbitre peut être récusé:

Lorsqu'il ne réponde pas aux qualifications convenues par les parties.. "

Disponible en : http://www.wipo.int/wipolex/fr/text.jsp?file $i d=270807$ 
cuestión dentro del mes siguiente a la revelación o al descubrimiento del hecho litigioso $(. . .)^{57}$

Por su parte la ley colombiana permite a través del artículo 76 (1) de la Ley 1563 que las partes acuerden el procedimiento aplicable para la recusación o que se remitan al reglamento de una institución de arbitraje. Si las partes no acordaron procedimiento alguno o si no se remiten a un reglamento institucional, la Ley prevé en el artículo 76 un procedimiento supletorio ${ }^{58}$.

Esto quiere decir que el único evento en el que el juez de apoyo intervendría sería en caso de aplicación del procedimiento supletorio del artículo 76, debido a que es en este supuesto cuando se prevé la intervención del juez local. En este caso cabría preguntarse sobre el procedimiento a seguir en caso de que, a pesar de haberse pactado entre las partes un procedimiento de recusación, o en caso de que aplique un reglamento institucional, no se pudiera solucionar la recusación de uno o varios de los árbitros, ¿podría intervenir el juez de apoyo? De otra parte, el artículo 75 impone como condición al árbitro para ejercer sus funciones una obligación de revelación similar a la del derecho francés, e incluye en la segunda parte otra posibilidad de recusación relativa a las calidades exigidas de las partes:

Artículo 75. Motivos de recusación (...) La persona a quien se le comunique su posible nombramiento como árbitro deberá revelar todas las circunstancias que puedan dar lugar a dudas justificadas acerca de su imparcialidad e independencia. El árbitro desde su momento de nombramiento y durante todas las actuaciones arbitrales revelara oportunamente tales circunstancias a las partes.

57 Código de procedimiento civil francés Articulo. 1456 " Le tribunal arbitral est constitué lorsque le ou les arbitres ont accepté la mission qui leur est confiée. A cette date, il est saisi du litige.

"Il appartient à l'arbitre, avant d'accepter sa mission, de révéler toute circonstance susceptible d'affecter son indépendance ou son impartialité. Il lui est également fait obligation de révéler sans délai toute circonstance de même nature qui pourrait naître après l'acceptation de sa mission.

"En cas de différend sur le maintien de l'arbitre, la difficulté est réglée par la personne chargée d'organiser l'arbitrage ou, à défaut, tranchée par le juge d'appui, saisi dans le mois qui suit la révélation ou la découverte du fait litigieux ». http://www. legifrance.gouv. fr/affichCodeArticle.do?cidTexte=LEGITEXTO 00006070716 \&idArticle $=$ LEGIARTI000023450865\&dateTex te=20130311. Traducción ver nota de página 14 supra.

58 Tomado del artículo 13 de la Ley Modelo.
Un árbitro sólo podrá ser recusado si existen circunstancias que den lugar a dudas justificadas respecto de su imparcialidad o independencia, o si no posee las calidades convenidas por las partes..." (Subrayado fuera de texto)

Las dos disposiciones en el derecho francés y colombiano son similares en lo que se refiere al deber de revelación, partiendo de su redacción, sin embargo la jurisprudencia y la doctrina francesa hacen una diferencia esencial entre el deber de imparcialidad e independencia y el deber de revelación, que no se encuentra presente en la práctica colombiana -a pesar de que la nueva ley 1563 en Colombia impone una obligación de información de los árbitros que se asemeja al de revelación-.

En efecto la jurisprudencia francesa comenzó a ser más exigente con respecto a la exigencia de la revelación por parte del árbitro. Ciertos autores consideraron que el deber de revelación había substituido el deber de independencia e imparcialidad ${ }^{59}$. Los árbitros tendrían la obligación de revelar a las Partes cualquier hecho que pudiera comprometer sus funciones durante el curso del proceso arbitral.

Según la doctrina, la independencia y la imparcialidad del árbitro, solo pueden ser garantizadas a través de la obligación de revelación. En efecto, el control de independencia y sobre todo el de la imparcialidad son tan subjetivos que la única manera de proceder es examinando, si los hechos objetados figuran o no en la declaración de independencia -que se desprende de la relevación de los miembros del tribunal-. Es el árbitro quien debe hacer conocer las circunstancias que puedan poner en duda su independencia, de esta manera pesa sobre él una verdadera obligación de transparencia frente a las partes.

Empero, la doctrina hace una diferencia clara entre la violación al deber de revelación y el de independencia del árbitro, porque solo una violación a esta última podría constituir un motivo de anulación de la sentencia. En efecto, teniendo en cuenta el alcance de la obligación de revelación, toda omisión de información de la parte del

59 CLAY, T. La disparition de l'obligation d'indépendance de l'arbitre au profit de l'obligation de révélation. REV. ARB. 2009.190. 
árbitro no puede considerarse como susceptible de afectar su independencia "(...)El no respeto de la obligación de revelación no constituye per se una falta que podría comprometer la responsabilidad de su autor pero no una causa de anulación de la sentencia (...)"60.

En derecho francés la obligación de revelación ha tenido un importante desarrollo jurisprudencial que nos permite apreciar los alcances de la obligación de imparcialidad, la cual cuenta a su vez con una relación directa con la obligación del árbitro que está investido "de una misión al mismo tiempo contractual y jurisdiccional que debe realizar en toda conciencia, independencia e imparcialidad" 61 "y que está relacionada directamente con el deber de lealtad que se impone respecto a las partes". ${ }^{62}$

La obligación de revelación impone al árbitro el deber de informar a las partes sobre todas las circunstancias que pudieran afectar su imparcialidad. Una vez en conocimiento de estas circunstancias deberán decidir sobre la aceptación, o no, del nombramiento del árbitro propuesto, o bien de su continuidad.

Si con conocimiento de causa las partes contestan de manera tardía la independencia del árbitro, puede configurase el rechazo del recurso de anulación. La Corte de Apelación de París decidió mediante sentencia del 10 de abril 2008:

60 HENRY, M. Le devoir d'indépendance de l'arbitre. Editorial L.G.D.J, 2001. "..Le non-respect de l'obligation de révélation est une faute susceptible d'engager la responsabilité de son auteur mais ne constitue pas per se une cause d'annulation de la sentence...»

61 Corte de Apelaciones de Paris, Pôle 2, Primera sala, 1èr de marzo de 2011, $n^{\circ}$ 09/22701, "Salomon X cl SAS Consultaudit». Refiriéndose a la misión del árbitro la Corte consideró que los árbitros estaban investidos " d'une mission à la fois contractuelle et jurisdictionnelle, qu'il doit remplir en toute consience, independance et impartialité".

62 El alcance de la obligación de independencia fue dada por la Corte de apelaciones de Paris en una sentencia del 20 de noviembre de 1997: "L'indépendance de l'arbitre est de l'essence de sa fonction juridictionnelle en ce sens que, d'une part il accède dès sa désignation au statu de juge exclusif par nature de tout lien de dépendance à l'égard des parties et que 'd'autre part, les circonstances invoquées pour contester cette indépendance doivent caractériser par l'existence de liens matériels ou intellectuels, une situation de nature a affecter le jugement de l'arbitre en constituant un risque certain de prévention à l'égard de l'une des parties à l'arbitrage " (3R cl phenix-Rivhelieu). Ver Corte de Apelaciones de Paris. Primera sala, sect C. Nov 1977, $n^{\circ}$ 96/82828.
La eficacidad del procedimiento arbitral y la cooperación entre las partes y el tribunal arbitral obligan a cada parte a invocar todas las irregularidades desde que ellas tengan conocimiento(...). ${ }^{63}$ (Traducción libre).

En el caso contrario, si el árbitro hubiera omitido revelar ciertas informaciones, la consecuencia sería la eventual anulación del laudo arbitral. Por esta razón los árbitros son cautelosos y prefieren revelar todas las informaciones, a veces en exceso y no siempre relevantes para el caso.

La jurisprudencia es abundante. El 20 de octubre de 2010, la primera sala civil de la Corte de Casación recordó los alcances de la obligación de revelación en cabeza de los árbitros y las razones por las cuales los árbitros deben revelar los elementos susceptibles de poner en duda su independencia:

(...) el carácter sistemático de la designación de una persona determinada por las sociedades de un mismo grupo, su frecuencia y su regularidad en un largo periodo, en contratos comparables, crearon una relación de negocios entre la persona y las sociedades del grupo que hacen parte del procedimiento, el árbitro tenía la obligación de revelar la integralidad de la situación a la otra parte para que esta estuviera en la medida de ejercer su derecho a la recusación(...) ${ }^{64}$ (Traducción libre).

Otra jurisprudencia del año 2011 tiene que ver con la negativa por parte de los árbitros de firmar la declaración de imparcialidad. La Corte de Apelación de Paris consideró que:

63 Corte de apelaciones de Paris. Primera sala, sect, 10 avr. 2008, $n^{\circ}$ 06/15636. ".. L'efficacité de la procédure arbitrale et la coopération entre les parties et le tribunal arbitral obligent toute partie à soulever tout moyen d'irrégularité dès qu'elle en a connaissance » (SAS C22 cl Jhon K Kiling and sons Ltd).

64 Corte de Casación. Primera sala civil. Arrêt $n^{\circ} 962$ del 20 de octubre $2010 n^{\circ}$ 09/68.131, Corte de Casación. Primera sala civil. Arrêt $n^{\circ} 963$ del 20 de octubre 2010 n09-68.997. «... le caractère systématique de la désignation d'une personne donnée par les sociétés d'un même groupe, sa fréquence et sa régularité sur une longue période, dans des contrats comparables, ont créé les conditions d'un courant d'affaires entre cette personne et les sociétés du groupe parties à la procédure de sorte que l'arbitre était tenu de révéler l'intégralité de cette situation à l'autre partie à l'effet de la mettre en mesure d'exercer son droit de récusation, la cour d'appel a violé les textes susvisés... » Disponible en http:// www.courdecassation.fr/jurisprudence_2/premiere_chambre civile_568/963_20_17862.html. 
(...) El rechazo no motivado de los árbitros de someterse a la obligación que les incumbe de satisfacer una demanda de declaración de intereses formulado por una de las partes, era de naturaleza a hacer dudar razonablemente de su independencia y de la imparcialidad del tribunal arbitral, adicionalmente, se estableció que el señor X, árbitro designado, participaba en otros arbitrajes donde las partes eran las mismas $(. . .)^{65}$ (Traducción libre)

En los dos casos citados las altas cortes sancionan las omisiones por parte de los árbitros de revelar la totalidad de las informaciones. El deber de información es corolario de la recusación pero sigue siendo una facultad de las partes. Ellas pueden decidir el no solicitarla.

Respecto del alcance de la obligación de revelación en Colombia, según la ley 1563 de 2012, dado que el texto es de adopción reciente, será necesario esperar que las altas cortes colombianas se pronuncien respecto a la extensión y contenido del deber de revelación de los árbitros.

Es común que, en ciertos tipos de eventos, en Colombia se encuentren en el mismo recinto árbitros y partes sin que por esta razón sea considerado que el deber de imparcialidad pueda ser objeto de discusión, a la diferencia con Francia, donde los árbitros son extremadamente precavidos para evitar problemáticas posteriores. Sin embargo, también es cierto que los casos que se conocen son anteriores al nuevo estatuto arbitral.

La nueva reglamentación creó una obligación más estricta a cargo de los árbitros de revelar todos los vínculos posibles con el caso o con las partes, el contencioso en Colombia sobre la materia apenas va a empezar y la práctica demostrará cómo lo manejan los distintos intervinientes. En todo caso, la no revelación de una información crucial por parte de un árbitro puede ser atacada en el futuro a través del recurso

65 Corte de apelaciones de París, pôle 1, Ch 1, 10 de marzo de $2011 R G n^{\circ}$ 09/21413. "le refus non motivé des arbitres de se soumettre à l'obligation qui leur incombe de satisfaire à une demande de déclaration d'intérêts formulée par une partie était de nature à faire raisonnablement douter celle-ci de l'indépendance, qui sont essence même de la fonction arbitrale, alors, en autre qu'il est établi que $M$.X arbitre désigné participait à d'autres arbitrages, mettant en cause les mêmes parties; » de anulación del artículo $108^{66}$ por indebida integración del tribunal arbitral.

A pesar de la ausencia de antecedentes importantes en Colombia de los casos de recusación contra los árbitros y la incertidumbre por parte de los practicantes sobre la manera de actuar en la materia, a nivel internacional se han desarrollado diversas normas que sirven de guía para los árbitros y los abogados, y que no son de obligatoria observancia, sin perjuicio de que las partes las adopten en el convenio arbitral.

Algunos ejemplos se encuentran en las Directrices de la IBA sobre los Conflictos de Intereses en el Arbitraje Internacional, el Code of Ethics for Arbitrators in Commercial Disputes de la AAA y los extractos de decisiones publicadas en la materia por la Corte de Arbitraje Internacional de Londres. Estos documentos pueden servir a los practicantes en Colombia para resolver dudas que tengan sobre posibles conflictos de intereses.

Una diferencia importante entre los dos sistemas de arbitraje en Francia y en Colombia es que el legislador colombiano incorporó, como causal de recusación, la ausencia de las competencias exigidas por las partes para desarrollar la actividad de árbitro.

Este tipo de disposiciones tiene como fundamento la naturaleza misma del arbitraje, que por ser convencional, radica en la voluntad de las partes. Establecer unas calificaciones mínimas por medio de acuerdo, en aspectos profesionales o técnicos, está basado en la misma libertad de pacto de los implicados. Sin embargo, esta causal debe ser aceptada bajo los límites de lo razonablemente exigible, para que no se convierta en una estrategia dilatoria en los procesos arbitrales.

El uso de la recusación como técnica dilatoria es una práctica que se ha desarrollado recientemente, incluso ante las instancias

66 Ley 1563 de 2012. Artículo 108 : “Causales de anulación. La autoridad judicial podrá anular el laudo arbitral a solicitud de parte o de oficio: d) Que la composición del tribunal arbitral o el procedimiento arbitral no se ajustaron al acuerdo entre las partes, salvo que dicho acuerdo estuviera en conflicto con una disposición de esta sección de la que las partes no pudieran apartarse o, a falta de dicho acuerdo, que no se ajustaron a las normas contenidas en esta sección de la ley". Ver nota de página 13 supra. 
arbitrales de la CCI. La recusación se ha triplicado según las estadísticas de la propia institución entre el periodo comprendido entre 1993 y $2006^{67}$ y solo un número mínimo de casos tenía un verdadero fundamento.

Ahora procederemos a dar algunas consideraciones respecto del remplazo de los árbitros.

\subsection{El remplazo del árbitro}

El remplazo o la sustitución del árbitro es un evento delicado que puede tener consecuencias jurídicas importantes en el curso del procedimiento arbitral. De una parte existe la problemática de los honorarios que han sido pagados al árbitro. De otra parte, las implicaciones de un proceso equitativo y si es necesario repetir la totalidad de actuaciones que habían sido adelantadas por el árbitro que será remplazado.

El criterio utilizado en la práctica francesa del arbitraje reside en el momento en que el remplazo del árbitro intervino. Si el reemplazo ocurre después de que el árbitro escucha a las partes en audiencia es altamente probable que se dé la necesidad de repetir las actuaciones.

En derecho francés, el artículo 1457 del código de procedimiento civil, prevé la intervención subsidiaria del juez de apoyo en caso de diferencias relacionadas con las razones invocadas por el árbitro para abandonar su misión arbitral:

Todo arbitro deberá desarrollar su misión hasta su término al menos que justifique la existencia de un impedimento o de una causa legítima de abstención o renuncia.

En caso de diferencia sobre la realidad del motivo invocado, el asunto será resuelto por la persona encargada de organizar el arbitraje, o en su defecto por el juez de apoyo a quien deberá someterse la demanda dentro del mes que sigue al impedimento, la abstención o la renuncia(..... ${ }^{68}$

67 CCI, Reporte estadístico, 14 (1) ICC. Ct. Boletín, 7, 11 (2003) Reporte estadístico-2006, 18 (1) ICC. Bull. 5, 9 (2007).

68 Código de procedimiento civil francés artículo 1457.

"Il appartient à l'arbitre de poursuivre sa mission jusqu'au terme de celle-ci à moins qu'il justifie d'un empêchement ou d'une cause légitime d'abstention ou de démission.

En cas de différend sur la réalité du motif invoqué, la difficulté est réglée par la personne chargée d'organiser l'arbitrage ou à défaut, tranchée par le juge d'appui saisi dans le mois qui suit
La ley colombiana estipula la intervención del juez de apoyo en los mismos casos en el artículo 77 de la ley de 2012.

Artículo 77. Falta o imposibilidad de ejercicio de funciones:

A falta de acuerdo de las partes:

1. Cuando el árbitro se vea impedido de jure o de facto para el ejercicio de sus funciones o no las ejerza dentro de un plazo razonable por el motivo que sea, cesará su cargo, si renuncia o si las partes acuerdan su remoción. De lo contario, si subsiste un desacuerdo respecto a alguno de estos motivos, cualquiera de las partes podrá solicitar a la autoridad judicial que declare la cesación del encargo, decisión que no tendrá recurso alguno.

2. La renuncia de un árbitro o el acuerdo de las partes para la cesación de sus funciones. No se considerara como aceptación de la procedencia de alguno de los motivos mencionados en el presente artículo o, si fuere el caso de los motivos del artículo $75(.$.

Nuevamente vemos cómo la disposición del derecho francés utiliza la figura del juez de apoyo como mecanismo subsidiario para resolver las dificultades relacionadas con el reemplazo, condicionándolo a que las partes estén de acuerdo y a que la institución de arbitraje escogida no prevea dentro de su reglamento otra solución ante esta eventualidad.

La intervención del juez es utilizada con más frecuencia en los arbitrajes ad hoc, teniendo en cuenta que raramente el compromiso o la cláusula compromisoria, estipulan mecanismos en este tipo de eventualidades.

En Colombia, la intervención del juez de apoyo como mecanismo subsidiario pareciera ser menos evidente, teniendo en cuenta que la institución encargada del arbitraje no es mencionada en la disposición. l'empêchement, l'abstention ou la démission...". Disponible en http://www.legifrance.gouv.fr/affichCodeArticle. do;jsessionid=001EA7D80D90C779215F5E1A5CDE2283.tpdjo0 $5 \mathrm{v}$ 3?idArticle $=$ LEGIARTI000023450846\& cidTexte $=$ LEGITEXTO $00006070716 \&$ dateTexte $=20130311 \&$ categorieLien $=i d \& o l d A c t i$ on=. Traducción ver nota de página 14 supra. 
Sin embargo, haciendo una lectura sistemática de las disposiciones en arbitraje internacional, podríamos concluir que la voluntad del legislador es la de favorecer la voluntad de las partes.

Esta es la conclusión de la lectura del artículo 64 de la ley 1563 de 2012:

(...) En la interpretación del arbitraje internacional habrán que tenerse en cuenta su carácter internacional y la necesidad de promover la uniformidad y la observancia de la buena fe.

... Cuando una disposición de la presente sección, excepto el artículo 101, deje a las partes la facultad de decidir libremente sobre un asunto, esta facultad entraña la de autorizar a un tercero, incluida la institución, para que adopte esa decisión.

Cuando una disposición de la presente sección, se refiera a un acuerdo que las partes hayan celebrado o que puedan celebrar o cuando, en cualquier forma, se refiera a un acuerdo entre las partes, se entenderán comprendidas en ese acuerdo todas las disposiciones del reglamento de arbitraje en el mencionado.

Asimismo el literal c del artículo 76 de la ley de 2012 sobre el procedimiento de recusación:

\section{Artículo 76. Procedimiento de recusación}

En el procedimiento de recusación del arbitraje internacional:

Las partes podrán acordar libremente el procedimiento de recusación de árbitros o someterse al procedimiento contenido en el reglamento arbitral.

A falta de acuerdo o de reglamento arbitral aplicable, se seguirán las siguientes reglas:

c. Si la otra parte conviene en la recusación o el árbitro renuncia, se procederá el nombramiento del árbitro sustituto en la misma forma que correspondía nombrar al árbitro recusado, salvo que se hubiera nombrado a un árbitro suplente $(\ldots)^{69}$

69 Ver nota de página 13 supra.
Así las cosas, en la ley 1563 de 2012 y en el Decreto de 2011, la intervención del juez es subsidiaria.

\section{EL CONTROL JUDICIAL POST LAUDO}

El control ejercido por los jueces sobre los laudos arbitrales es un control a posteriori y, en principio, limitado. A pesar de la consagración de principios rectores en el arbitraje internacional, como el principio de competencia-competencia, los sistemas nacionales no otorgan al árbitro una jurisdicción exclusiva sobre los asuntos sometidos al arbitraje y el alcance del convenio arbitral, sino una jurisdicción primaria, luego revisable judicialmente, aunque, en las jurisdicciones proarbitraje, de manera limitada ${ }^{70}$.

La competencia para ejercer esta función se encuentra en cabeza de autoridades judiciales diferentes al juez de apoyo. En el caso colombiano encontramos la intervención de la Corte Suprema de Justicia para la anulación y reconocimiento de laudos arbitrales extranjeros o, en caso de existencia de una entidad pública, la sección tercera del Consejo de Estado. Para el caso francés el recurso de anulación la competencia es de la Cour d'appel (Corte de apelaciones) y para el reconocimiento de sentencias arbitrales internacionales, el Presidente del tribunal de Grande Instance.

El juez puede efectuar su control a posteriori a través de cuatro procedimientos que analizaremos sucesivamente: el recurso de anulación, el trámite de reconocimiento de las sentencias arbitrales, el recurso de apelación contra la ordenanza que niega el exequátur en Francia y, para el caso colombiano, el control de constitucionalidad; aunque en este caso, hasta el momento, solo se ha dado un control sobre los laudos proferidos en arbitraje nacional.

\subsection{El recurso de anulación}

En términos generales, el recurso de anulación permite a los jueces revisar la validez del laudo, verificando únicamente si se configura alguna de las causales taxativamente señaladas por la ley. El objetivo es que las partes puedan tener acceso a

70 ROQUE I CAIVANO, Retos del arbitraje frente a la administración de justicia. Disponible en: http://www. castillofreyre.com/biblio_arbitraje/vol5/DIA-1-2.pdf. 
una instancia judicial, si lo consideran necesario, pero de manera limitada, lo que evidencia la confianza y el respeto de las legislaciones frente a este mecanismo de resolución de conflictos.

Veremos la manera como las dos legislaciones, objeto de nuestro estudio, codifican el recurso de anulación contra los laudos en el arbitraje internacional, proferidos en el territorio nacional (4.1.1); para luego concentrarnos en una de las novedades francesas del Decreto de 2011 respecto a la posibilidad de renunciar al recurso de anulación y la consagración del mismo principio en Colombia en La ley 1563 de 2012. (4.1.2)

\subsubsection{La consagración del recurso de anulación}

En derecho francés el artículo $1520^{71}$ del Código de Procedimiento Civil enumera de manera taxativa las causales de anulación de un laudo arbitral internacional:

Art. 1520. El recurso de anulación sólo podrá interponerse si:

1. el tribunal arbitral se ha declarado erradamente competente o incompetente

2. el tribunal arbitral fue constituido de forma irregular o

3. el tribunal arbitral decidió sin atenerse a la misión que le había sido confiada o

4. no se ha respetado el principio de debate contradictorio o

5. el reconocimiento o la ejecución del laudo son contrarios al orden público internacional (...).

71 Código de procedimiento civil francés artículo 1520. Le recours en annulation n'est ouvert que si :

$1^{\circ}$ Le tribunal arbitral s'est déclaré à tort compétent ou incompétent ou

$2^{\circ}$ Le tribunal arbitral a été irrégulièrement constitué ou

$3^{\circ}$ Le tribunal arbitral a statué sans se conformer à la mission qui lui avait été confiée ou

$4^{\circ}$ Le principe de la contradiction n'a pas été respecté ou

$5^{\circ}$ La reconnaissance ou l'exécution de la sentence est contraire à l'ordre public international... »

Disponible en http://www.legifrance.gouv.fr/affichCodeArticle. do?idArticle $=$ LEGIARTI000023427702\&cidTexte $=$ LEGITEXT000 006070716\&dateTexte $=20130526 \&$ oldAction $=$ rechCodeArticle . Traducción ver nota de página 14 supra.
Colombia, por su parte, incorpora por medio de la Ley 1563 de 2012, en el artículo 108, el recurso de anulación de la siguiente manera:

Causales de anulación. La autoridad judicial podrá anular el laudo arbitral a solicitud de parte o de oficio:

1. A solicitud de parte, cuando la parte recurrente pruebe:

a) Que para el momento del acuerdo de arbitraje estaba afectada por alguna incapacidad; o que dicho acuerdo no es válido en virtud de la ley a que las partes lo han sometido, o si nada se hubiera indicado a este respecto, en virtud de la ley colombiana; o

b) Que no fue debidamente notificada de la designación de un árbitro o de la iniciación de la actuación arbitral o no pudo, por cualquiera otra razón, hacer valer sus derechos; 0

c) Que el laudo versa sobre una controversia no prevista en el acuerdo de arbitraje o contiene decisiones que exceden los términos del acuerdo de arbitraje. No obstante, si las disposiciones del laudo que se refieren a las cuestiones sometidas al arbitraje pueden separarse de las que no lo están, sólo se podrán anular estas últimas; o

d) Que la composición del tribunal arbitral o el procedimiento arbitral no se ajustaron al acuerdo entre las partes, salvo que dicho acuerdo estuviera en conflicto con una disposición de esta sección de la que las partes no pudieran apartarse o, a falta de dicho acuerdo, que no se ajustaron a las normas contenidas en esta sección de la ley.

\section{De oficio, cuando:}

a) Según la ley colombiana, el objeto de la controversia no es susceptible de arbitraje; o,

b) El laudo sea contrario al orden público internacional de Colombia (...).

A pesar de que la terminología en las dos legislaciones es diferente, las causales de anulación en los dos sistemas son similares, salvo por ciertas excepciones a las que nos referiremos a continuación. 
En primer lugar, la ley 1563 de 2012 faculta a la autoridad judicial para pronunciarse de oficio respecto de ciertas causales de anulación previstas contra el laudo arbitral, mientras que en derecho francés, estas deben ser objeto de una solicitud específica de las partes.

Es decir, que si la sede del arbitraje escogida por las partes es Colombia, las autoridades judiciales pueden pronunciarse oficiosamente sobre la nulidad de los laudos arbitrales en dos casos: (i) cuando el laudo arbitral viola el orden público internacional de Colombia o; (ii) cuando el litigio que fue dirimido por el árbitro no era susceptible de arbitraje ${ }^{72}$. Además, la legislación colombiana contempla una particularidad: las partes pueden renunciar al recurso de anulación o a ciertas de las causales previstas por la Ley para el recurso de anulación. Si las partes renuncian al recurso de anulación es claro que el juez no podría conocer del eventual recurso, razón por la cual no se puede hablar de pronunciamientos de oficio contemplados en el artículo 108. Asimismo, en caso de que las partes renuncien a algunas de las causales, se debe entender que pueden solo renunciar a aquellas que tienen disponibles, pero no a las que el juez puede declarar de oficio.

De cualquier modo, consideramos que la posibilidad para las autoridades judiciales de pronunciarse oficiosamente sobre las causales de nulidad es de difícil aplicación, teniendo en cuenta que cuando una de las partes decide hacer uso de la demanda de anulación del laudo arbitral, invocara por ella misma todas las causales que considera pueden existir; sin exponerse al riesgo de que la autoridad judicial no las contemple en su decisión.

¿Sería posible, en el caso colombiano, que la Corte Suprema de Justicia pueda negar el reconocimiento de un laudo realizado en el extranjero, con fundamento en una causal de nulidad de la sentencia arbitral? La ley 1563 de 2012 no hace referencia a esta posibilidad pero nada impediría que esta situación se presentara. Nuevamente la jurisprudencia declara más tarde la posición de las autoridades judiciales colombianas.

72 En derecho francés esta causal equivale a la expresión "cuando el tribunal arbitral se ha declarado erradamente competente o incompetente".
En Francia esta posibilidad existe, por ejemplo en la jurisprudencia Soerni ${ }^{73}$, - no se trataba de un recurso de anulación, sino del procedimiento de reconocimiento y ejecución de un laudo inglés en Francia - la Corte de Casación analizó igualmente la validez del convenio arbitral, a solicitud de la parte que se oponía al reconocimiento de la sentencia arbitral.

Así las cosas, en el derecho francés, aunque el juez no tenga específicamente la posibilidad de invocar causales de nulidad que no fuesen alegadas por las partes, el juez puede rechazar el reconocimiento y la ejecución de un laudo arbitral. Sin embargo, este tipo de control es muy limitado y solo una contrariedad al orden público internacional justificaría tal rechazo.

El rechazo también puede justificarse por una de las causales de anulación. Así el artículo 1514 del Código de Procedimiento Civil, establece que los laudos arbitrales son reconocidos en Francia si su existencia fue establecida por quien demanda el reconocimiento y si no es contraria al orden público internacional. El último inciso del artículo 1525, del mismo código, también establece que la Corte de Apelaciones puede negar el reconocimiento o el exequátur del laudo arbitral, solo en los casos establecidos en el artículo 1520, los cuales no son otros que las causales para solicitar la anulación de la sentencia.

A diferencia del derecho francés, que remite como causales para negar la solicitud del exequátur a las causales de nulidad del laudo, la Ley 1563 de 2012 hace la diferencia entre causales de nulidad y causales de negación del exequátur de manera taxativa y separada. Nos referiremos a ellas en la parte dedicada al reconocimiento y ejecución de sentencias arbitrales que veremos posteriormente.

\subsubsection{La renuncia al recurso de nulidad}

Una de las novedades introducidas por el Decreto del 2011, en su artículo 1522, es la facultad de las partes de renunciar expresamente y mediante una convención especial al recurso de anulación. El decreto no hace mención de una fórmula precisa para la redacción de la convención, la única condición es que las partes

73 Corte de Casación de 8 de julio de 2009, "Soemi c/ société Air Sea Broker Ltd". 
expresen sin ambigüedad que renuncian al recurso ${ }^{74}$.

Esta disposición en derecho francés está inspirada en el arbitraje suizo y se encuentra prevista en muy pocas legislaciones. En Francia el recurso a esta renuncia no está condicionado a que las partes tengan o no su domicilio, ni su residencia, ni su establecimiento en el territorio, como existe en otras legislaciones extranjeras que adoptaron esta opción, tales que la belga o la sueca. Esto significa también, que no se hacen consideraciones respecto de la nacionalidad de las partes.

La posibilidad de la renuncia al recurso de anulación en Colombia es más limitado, la Ley 1563 de 2012 contempla en el artículo 107, parágrafo dos, la posibilidad de renunciar al recurso de anulación para las partes, siempre y cuando no cuenten con su domicilio o residencia en Colombia. En Colombia el recurso de anulación procede contra los laudos arbitrales, sin embargo, un laudo arbitral no es solo la decisión final sobre el fondo del litigio.

Puede existir así, por ejemplo, un primer laudo sobre la existencia, o no, de responsabilidad, y un segundo laudo sobre la indemnización de perjuicios. Los dos laudos podrían ser atacados mediante el recurso de anulación. De otro lado, las medidas cautelares pueden decretarse, o no, mediante un laudo, susceptible de recurso de anulación. Esto puede facilitar una eventual ejecución del laudo en el extranjero. Adicionalmente, la medida cautelar puede atacarse también mediante la solicitud de negación de la ejecución de la medida cautelar

La posibilidad y validez de la renuncia al recurso de anulación en Francia y en Colombia, hacen de ellos países favorables al arbitraje internacional. Eliminar el recurso de anulación del laudo es un paso hacia la deslocalización del arbitraje, lo que a su vez fortalece la convención de New York, y lo deja como instrumento único de control de los laudos, que será en todo caso la red

74 La exigencia de la estipulación escrita existe en la Convención de New York, Artículo II, Artículo 7(2) de la Ley modelo sobre Arbitraje Comercial Internacional de la CNUDMI entre otras. protectora y que asegura la libre circulación del laudo $^{75}$.

En todo caso, en Francia, aunque las partes renuncien a la anulación, tendrán la oportunidad de recurrir al recurso de apelación contra la decisión que admite el exequátur sobre el fundamento de las mismas causales previstas para la anulación. Vale la pena recordar que en Francia, en principio, no existe recurso en arbitraje interno e internacional contra la decisión que acuerda o autoriza el exequátur, solo contra la decisión que lo rechaza, sin embargo, en caso de renuncia del recurso de anulación, se permite la apelación de la decisión de admisión del exequátur del laudo.

Igualmente el caso colombiano consagra un mínimo de protección judicial. En la Ley 1563 de 2012 , la regla general hace que los laudos no sean objeto del procedimiento de reconocimiento y ejecución de la sentencia, salvo en el caso que las partes hubieran renunciado a la anulación, caso en cual la sentencia arbitral será el objeto del control por parte de las autoridades judiciales. Cabe recordar que en Colombia, en caso de arbitraje internacional, no existe el recurso de revisión del laudo arbitral.

De esta manera, a pesar de que las dos legislaciones otorgan a las partes la oportunidad de renunciar a la anulación, también les proporciona ciertas garantías.

\subsection{El recurso de apelación.}

En derecho francés, el recurso de apelación está reservado a las ordenanzas que niegan el exequátur de los laudos arbitrales en materia interna o internacional rendidas en el extranjero o cuando en materia internacional las partes han renunciado al recurso en anulación. Los artículos 1525 y siguientes del Código de Procedimiento Civil consagran las condiciones para solicitar el recurso:

“... Art. 1525. El auto que decide sobre una solicitud de reconocimiento o de exequátur de un laudo arbitral dictado en el extranjero es susceptible de apelación. La apelación se interpondrá en un plazo de un mes contado a partir de la notificación de

75 JIMENEZ FIGUERES, Dyalà Jimenez. Renuncia al recurso de anulación contra el laudo: Alcances y análisis comparativo. Arbitraje comercial y arbitraje de inversión. Páginas 531-537. 
la decisión Sin embargo, cuando la apelación se interponga contra el laudo en el que conste ya el exequátur, las partes podrán convenir otro modo de comunicación. La Corte de apelaciones sólo podrá denegar el reconocimiento o el exequátur del laudo arbitral por los motivos previstos en el artículo $1520 \ldots{ }^{\prime \prime 6}$

Por el contrario, el derecho colombiano no contempla la posibilidad de un recurso de apelación en caso de no reconocimiento y ejecución de los laudos arbitrales. El artículo 113 de la Ley 1563 de 2012 contempla:

(...) Artículo 113. Competencia funcional. La decisión adoptada por la autoridad judicial competente en el trámite de reconocimiento de los laudos que conforme a la presente sección demanden del mismo se tramitará en única instancia y contra ella no procederá recurso o acción alguna (...).

La redacción de los dos legisladores nos permite establecer, una vez más, la tendencia liberal del Decreto 2011 en Francia respecto al reconocimiento y la ejecución de los laudos arbitrales.

Estableciendo un recurso de apelación contra la ordenanza que niega el exequátur de los laudos arbitrales, el legislador Francés da una última oportunidad a las partes para hacer efectiva la decisión en el ámbito jurídico francés.

La autoridad judicial no va a pronunciarse sobre el fondo del asunto que fue el objeto del litigio sino sobre la ordenanza que negó el exequátur, basándose en las causales establecidas en el artículo 1520 del Código de Procedimiento Civil, que, como explicaremos, consiste en un

76 Artículo 1525 código de procedimiento civil francés. « La décision qui statue sur une demande de reconnaissance ou d'exequatur d'une sentence arbitrale rendue à l'étranger est susceptible d'appel.

L'appel est formé dans le délai d'un mois à compter de la signification de la décision.

Les parties peuvent toutefois convenir d'un autre mode de notification lorsque l'appel est formé à l'encontre de la sentence revêtue d'exequatur.

La cour d'appel ne peut refuser la reconnaissance ou l'exequatur de la sentence arbitrale de dans les cas prévus à l'article $1520 . . . »$. Disponible en http://www.legifrance.gouv.fr/affichCodeArticle. do;jsessionid=621E3A337FE4397A652EA90D9A08BE6D.tpdjo $07 v \_$2?idArticle $=$LEGIARTI000023430205\&cidTexte $=$LEGITEXT 000006070716\&dateTexte $=20121203$. Traducción ver nota de página 14 supra. control mínimo. El Decreto 2011 favorece la eficacia del arbitraje internacional

\subsection{El reconocimiento y ejecución de los laudos arbitrales}

El trámite de reconocimiento y ejecución de los laudos arbitrales es un procedimiento que tiene como objetivo obtener la fuerza ejecutoria de una decisión que fue proferida en el extranjero.

Un laudo arbitral internacional es definido en derecho francés como una decisión de justicia internacional que no está ligada a ningún orden judicial estatal. Como consecuencia la autoridad judicial deberá, al momento de la demanda de su reconocimiento y ejecución en el territorio, apreciar su regularidad respecto del derecho francés ${ }^{77} \mathrm{y}$ en el procedimiento para el mismo que se encuentra codificado en los artículos 1514, 1515, 1516, y 1517 del Código de Procedimiento Civil.

Es precisamente por estas razones que ciertas sentencias arbitrales que han sido anuladas en su Estado de origen pueden ser reconocidas y ejecutadas en Francia.

La jurisprudencia francesa consideró que la validez de un laudo arbitral no debe ser evaluada solamente teniendo en cuenta la ley de la sede del arbitraje, sino también la ley donde deberá ser ejecutoriada, la cual tiene iguales o más facultades para hacerlo ${ }^{78}$. Es decir que, a pesar de haber sido anulada en otro país, si la sentencia cuenta con las condiciones establecidas por la jurisprudencia y la legislación vigente, podrá ser objeto de un reconocimiento y una ejecución en el Estado Francés.

Varias decisiones de las altas Cortes ilustran las tendencias de las últimas décadas respecto al tema, encontramos por ejemplo la jurisprudencia de la Corte de Casación desde los años ochenta con el célebre caso Société Pabalk Ticaret v. Société Norsolor ${ }^{79}$, posteriormente Hilmarton v.

77 Casación Civil, Sala primera, 23 de marzo de 1994, Rev. Arb. 1994.327, nota JARRONSON Ch ; Rev. Crit. DIP., 1995. 956, nota OPPETIT B. ; JDI, 1994. 701.

78 GAILLARD, Emmanuel. L'exécution des sentences annulées dans leur pays d'origine, Journal du Droit international, 125" année (1998) No 3 - Juillet-Août-Septembre.

79 Société Pabalk Ticaret Ltd. Sirketi v. Société Norsolor. Corte de Casación de París (9 de octubre, 1984), 2 Journal of International 
Omnium de Traitement y de Valorisation, OTV, pero también uno de los casos más relevantes es la decisión de la Corte de Casación en el caso Putrabali ${ }^{80}$.

En esta sentencia la Corte de Casación confirmó la decisión de la Corte de Apelaciones de París sobre el exequátur del laudo arbitral de la siguiente manera:

El laudo internacional, que como tal no hace parte de ningún sistema jurídico estatal, es una decisión de justicia de carácter internacional cuya validez debe ser apreciada según las normas aplicables en el país en el cual se pide su reconocimiento o ejecución; ... en aplicación del artículo VII de [la Convención], la compañía Rena Holding tenía derecho a invocar en Francia el laudo de 10 de abril de 2001 dictado en Londres, en aplicación del convenio arbitral y del reglamento de la IGPA, y a prevalerse de las disposiciones del derecho francés de arbitraje internacional que no contempla la anulación del laudo en el país de origen como motivo de rechazo del reconocimiento y ejecución del laudo dictado en el extranjero(...)

De esta manera, la jurisprudencia considera que la declaración de la nulidad de la sentencia arbitral, en el estado sede del arbitraje, al no estar consagrada dentro de las causales para negar el reconocimiento de la sentencia arbitral en Francia, en aplicación del artículo VII de la Convención de Nueva York, puede ser reconocida y ejecutada en Francia $^{81}$.

Esta posibilidad de reconocimiento de sentencias anuladas en el extranjero no está contemplada en la legislación colombiana.

Frente a los aspectos generales de reconocimiento y ejecución de la sentencias

Arbitration, 67. XI Yearbook of Commercial Arbitration, YBCA, 484 (1986). 24 International Legal Materials, ILM, 360 (1985).

80 PT Putrabali Adyamulia v. Rena Holding. Nos. 05-18053 y 06-13293, Corte de Casación (29 de junio, 2007). I Bulletin Civil, 250, 251. Revue de l'Arbitrage, 507 (2007). MANTILLA-SERRANO Fernando. Panorama de jurisprudencia francesa (Capítulo francés del Club Español del Arbitraje): Comentario sobre la decisión de la Cour d'Appel (1 1 a Sala Civil) de 29 de junio de 2007 PT Putrabali Adyamulia c. Rena Holding, 3 Spain Arbitration Review, 106 (2008).

81 MANTILLA SERRANO Fernando, Algunos apuntes sobre la ejecución de los laudos anulados y la convención de Nueva York. Int. Law: Rev. Colomb. Derecho Int. no.15 Bogotá July/Dec. 2009. arbitrales, Francia, al ser parte de los países que firmaron la Convención por el reconocimiento y la ejecución de las sentencias arbitrales de junio de 1958 o "Convención de New York", reconoce la autoridad de un laudo arbitral y acepta la ejecución del mismo conformemente a sus reglas de procedimiento.

Dos condiciones son esenciales para adelantar el procedimiento de exequátur: (i) que la parte que invoca el reconocimiento del laudo establezca su existencia, y (ii) que el laudo arbitral no sea manifiestamente contrario al orden público internacional, de manera flagrante, efectiva y concreta $^{82}$.

Se trata de un procedimiento no contradictorio que debe demandarse ante el Tribunal de Grande Instance, sin embargo, la ley exige que en caso de rechazo al exequátur, la ordenanza sea motivada. La condición de que el laudo arbitral no esté en contra del orden público internacional es una concepción minimalista del orden público con el objetivo de que las autoridades judiciales no se pronuncien sobre el fondo del litigio.

Varios ejemplos jurisprudenciales ilustran la posición de la Corte de Casación francesa en este sentido. Podemos mencionar la sentencia del 6 de mayo de 2009, International Company For comercial Exchanges (Income), en la cual se rechazó el exequátur dado que la sentencia había condenado a una de las partes en violación de la regla de orden público internacional sobre la suspensión de acciones individuales.

Por su parte, la consagración del reconocimiento y la ejecución en Colombia de los laudos arbitrales en Ley de 2012 establece en sus artículos 111 y siguientes, las condiciones para el reconocimiento de los laudos arbitrales internacionales en Colombia.

En primer lugar, el articulo 111 precisa que los laudos internacionales, cuya sede sea Colombia, serán considerados como laudos nacionales y podrán ser ejecutados directamente, salvo si las partes decidieron renunciar al recurso de anulación, hipótesis en la cual el reconocimiento es necesario.

82 Ver en la jurisprudencia Corte de Casación, 9 de marzo de 2011, Société Chantiers de l'Atlantique (CAT) /Société Gaz Transport et Tecnigaz (GTT). 
Es una diferencia importante con respecto al derecho Francés, dado que en Francia se exige un trámite de exequátur para los laudos arbitrales internacionales, a pesar de que la sede de arbitraje sea en Francia; como consecuencia lógica de la jurisprudencia que considera que las sentencias internacionales no están ligadas a ningún orden estatal.

En lo que se refiere al exequátur de los laudos arbitrales internacionales en general, el Estado colombiano también hace parte de los países que ratificó la Convención de New York de 1958, al igual que Francia, aunque también la convención de Panamá de 1975.

Esta nueva consagración legal en la Ley 1563 de 2012, pone fin a los procedimientos de exequátur que se realizaban bajo el imperio de las disposiciones legales anteriores, las cuales hacían de este procedimiento un trabajo complejo y lleno de condiciones; por lo tanto se asimilaban más a un proceso judicial que al simple reconocimiento de un laudo arbitral. ${ }^{83}$

De otra parte, el artículo 112 de La ley 1563 de 2012 incluye las causales taxativas por las cuales las autoridades judiciales pueden rechazar el reconocimiento y la ejecución del laudo, calcadas de la Convención de New York y la de Panamá ${ }^{84}$.

Artículo 112. Motivos para denegar el reconocimiento:

Solo se podrá denegar el reconocimiento del laudo arbitral, cualquiera que sea el país en que se haya dictado, en los casos y por las causales que se indican taxativamente a continuación:

a. A la instancia de la parte contra la cual se invoca, cuando ella pruebe ante la autoridad judicial competente del país en que se pide el reconocimiento o la ejecución:

i. Que para el momento del acuerdo de arbitraje estaba afectada por alguna incapacidad; o que dicho acuerdo no es válido en virtud de la ley a que las partes lo han sometido, o si nada se

83 BERNAL GUITIERREZ Rafael, "El arbitraje internacional dentro del nuevo estatuto del arbitraje en Colombia", XXXIII Congreso Colombiano de derecho procesal, Universidad libre de Colombia, páginas 280 y siguientes.

84 Ver nota de página 78 supra. hubiera indicado a ese respecto, en virtud de la ley del país en que se haya dictado el laudo; o

ii. Que la parte contra la cual se invoca el laudo no fue debidamente notificada de la designación de un arbitraje o de la iniciación de la actuación arbitral o no pudo, por cualquiera otra razón, hacer valer sus derechos; o

iii. Que el laudo versa sobre una controversia no prevista en el acuerdo de arbitraje o contiene decisiones que exceden los términos del acuerdo de arbitraje. No obstante, si las disposiciones del laudo que se refieren a las cuestiones sometidas al arbitraje pueden separarse de las que no lo están, se podrá dar reconocimiento y ejecución a las primeras; 0

iv. Que la composición del tribunal arbitral o el procedimiento arbitral no se ajustaron al acuerdo celebrado entre las partes o, en defecto de tal acuerdo, a la ley del país donde se adelantó o tramito el arbitraje o

v. Que el laudo no es aun obligatorio para las partes o fue anulado o suspendido por la autoridad judicial del país sede del arbitraje; o

b. Cuando la autoridad judicial competente compruebe:

i. Que, según la ley colombiana, el objeto de la controversia no era susceptible de arbitraje; o

ii. Que el reconocimiento o la ejecución del laudo serian contrarios al orden público internacional de Colombia..."

El trámite del exequátur de la Ley 1563 de 2012 es un trámite de única instancia contra el cual no procede recurso alguno.

A diferencia con el derecho francés, el trámite es contradictorio. En derecho francés, el artículo 1516 del Código del Procedimiento Civil establece que el procedimiento de exequátur no es contradictorio. Una vez que se da el auto admisorio de la demanda, el juez corre traslado a la contraparte. La ley impone adicionalmente al juez un plazo máximo de 20 días para pronunciarse. 
En conclusión, las dos legislaciones estudiadas muestran su apertura al arbitraje y a la circulación de las sentencias arbitrales internacionales. Al formar parte de los Estados que firmaron la Convención de New York no solo se alinean a las tendencias internacionales del arbitraje, sino que también proporcionan a las partes las garantías necesarias para poder ejecutar los laudos; ciertas diferencias persisten pero ninguna tan significativa para obstaculizar el procedimiento. Francia ha sido, y sigue siendo, una de las sedes principales del arbitraje internacional. Colombia, con su nueva legislación, ya tiene una herramienta interesante para desarrollarse como un centro, al menos regional, del arbitraje internacional.

\subsection{Control del juez de tutela}

Por ser una particularidad del sistema del arbitraje en Colombia, en comparación con el sistema legal francés del arbitraje, estamos obligados a revisar en nuestro estudio una de las fragilidades del sistema, relacionada con lo que algunos autores han denominado la " $\mathrm{La}$ constitucionalización del arbitraje $e^{\prime 85}$, un fenómeno que se ha venido presentando en ciertos países latinoamericanos y que tiene relación con la incidencia del derecho constitucional en el arbitraje.

El interés académico por la dimensión constitucional fue tratado de manera global por primera vez en 2006, en el III congreso internacional de la Asociación Andrés Bello de juristas franco-latino-americanos, sobre la "Constitucionalización del derecho privado"86, realizado en la ciudad de Bogotá. Esta "constitucionalización" ha sido el objeto de múltiples estudios por parte de diferentes autores, quienes han alertado sobre las consecuencias negativas de la intervención de la teoría constitucionalista en el arbitraje internacional.

Aplicado al caso colombiano, desde antes de la expedición de la Ley 1563 de 2012, sobre el arbitraje nacional e internacional, ha existido el

85 DE JESÚS O, Alfredo. La autonomía del arbitraje comercial internacional a la hora de la constitucionalización del arbitraje en América Latina. Publicado en Estudios de derecho privado en Homenaje a Christian Larroumet. Universidad del Rosario, Bogotá, 2008.

86 LARRAUMET Christian, (Dir.), Constitucionalización del Derecho Privado, Association Andrés Bello des juristes francolatino-américains - Universidad Externado de Colombia Universidad del Rosario, Bogotá, 2007. debate en torno a la protección de los derechos fundamentales consagrados en la Constitución Política de 1991 y sus incidencias sobre el arbitraje.

Nos referiremos entonces en esta parte al fundamento constitucional de la acción de tutela contra el laudo arbitral, revisaremos en una parte subsiguiente la evolución jurisprudencial de las altas cortes colombianas en la materia, posteriormente la relación entre el recurso de nulidad y la acción de tutela para finalizar con la pregunta sobre la procedencia de la acción de tutela en el arbitraje colombiano después de la Ley 1563 de 2012.

\subsubsection{El fundamento constitucional de la acción de tutela contra el laudo arbitral}

El arbitraje ha sido descrito en la Constitución como una función jurisdiccional en donde los particulares quedan investidos de la función de administrar justicia de manera temporal ${ }^{87}$, y así como administran justicia, deben hacer respetar los derechos de la Carta política de la misma manera que lo hace un juez de la república.

La acción de tutela en el ordenamiento jurídico colombiano permite proteger los derechos fundamentales a través de la intervención de un juez que ordena, en el caso que considere necesario, la intervención de la autoridad pública para que el responsable o responsables de la violación, realicen un acto positivo encaminado a proteger el derecho fundamental, o a cesar los actos de violación para la preservación del derecho.

Relacionado con las sentencias judiciales, se ha admitido la procedencia de la acción cuando estas violan derechos fundamentales, si la violación es manifiestamente contraria a derecho, pudiéndose calificar como una vía de hecho.

Aplicados al objeto de nuestro estudio, la procedencia de la acción de tutela contra los laudos arbitrales encontraría su fundamento,

87 Constitución Política de Colombia de 1991. Artículo 116, Inc. 4: "Los particulares pueden ser investidos transitoriamente de la función de administrar justicia en la condición de jurados en las causas criminales, conciliadores o en la de árbitros habilitados por las partes para proferir fallos en derecho o en equidad, en los términos que determine la ley". 
teniendo en cuenta que son considerados como sentencias judiciales ${ }^{88}$.

Así las cosas los jueces pueden llegar a modificar la decisión de un tribunal de arbitraje a través de la acción de tutela, lo cual comporta una grave vulneración a los principios del arbitraje en donde existen recursos específicos consagrados para atacar el laudo. Desafortunadamente el papel de la jurisprudencia de las altas cortes ha contribuido en este proceso.

4.4.2 La evolución jurisprudencial de la procedencia de la acción de tutela contra los laudos arbitrales

Fue a partir del año 2002 cuando la Corte Constitucional se refirió a la procedencia de la acción en caso de vías de hecho que vulnerarán derechos fundamentales y fue más lejos, aceptando la acción de tutela como mecanismo transitorio, antes de que el laudo fuera proferido. De manera general, la situación se configura por violaciones al debido proceso ${ }^{89}$.

En el 2005 la Corte Constitucional anuló la primera decisión arbitral. En esta oportunidad la máxima jurisdicción anuló la decisión arbitral y la sentencia del Consejo de Estado $^{90}$ que había denegado el recurso de anulación contra el laudo, basado en la violación del debido proceso. La Corte consideró que con su decisión, el Consejo de Estado había violado derechos fundamentales ${ }^{91}$; esto, a pesar de que el Consejo de Estado tiene la misma jerarquía que la Corte Constitucional en Colombia ${ }^{92}$.

Ante estas decisiones contradictorias de las altas Cortes, la Corte Constitucional, por medio de Sentencia de Unificación, se pronunció en el año 2007 en el sentido de que, si bien en principio, la tutela no procede contra los laudos arbitrales, podría proceder si se incurren en vías

88 Consejo de Estado. SCA. Sección tercera. Primero de agosto de 2002. Electrificadora del Atlántico S.A. E.S.P. contra Termorío S.A. E.S.P.

89 Corte Constitucional. Sentencia SU-837 de 2002.

90 Consejo de Estado. SCA. Sección tercera. 11 de marzo de 2004.

91 Corte Constitucional. Sentencia T-481 del 11 de mayo de 2005. Exp. T-980611. Sin embargo, esta decisión fue revocada mediante Sentencia de la misma Corte Constitucional SU-174 de 2007

92 ZULETA LONDOÑO, Alberto. La protección constitucional del arbitraje. EN : Arbitraje Internacional - Tensiones Actuales. Fernando Mantilla-Serrano. Legis. 2007 de hecho que vulneren un derecho fundamental ${ }^{93}$. Esta afirmación fue confirmada por la Corte Constitucional en el año $2008^{94}, 2009^{95}, 2010^{96}$ y 2011 en donde se aceptó la procedencia, aunque de manera excepcional, de la acción de tutela contra los laudos arbitrales.

Así por ejemplo la alta Corte anuló un laudo arbitral mediante sentencia T-466 de 2011 ya que los árbitros:

(i) Ignoraron el carácter inequívoco de las conclusiones del primer dictamen pericial en cuanto a la falta de confiabilidad de la contabilidad del sistema como fundamento para el cálculo de las pérdidas operativas;

(ii) fundamentaron su decisión única y exclusivamente en el anexo 1.1. de la aclaración del primer dictamen pericial, a pesar de que aquel señalaba de manera textual que las cifras allí consignadas no podían tenerse como confiables; (iii) inadvirtieron que los cuestionamientos realizados a dicha prueba en lo relativo al carácter impreciso de la estimación de las pérdidas nunca fueron abordados, ni siquiera tangencialmente, por la pericia decretada para resolver la objeción por error grave planteada y (iv) no consideraron aquellas otras pruebas que corroboraban la falta de confiabilidad del sistema de acueducto. ${ }^{97}$

Además de esto agregó que la procedencia de la solicitud de amparo está subordinada a:

(i) El agotamiento de los recursos previstos en la ley para atacar la decisión arbitral y (ii) la configuración de una vía de hecho, al verificarse la existencia de un actuar manifiestamente caprichoso e irrazonable por parte de los árbitros, encausado en cualquiera de los defectos desarrollados por la jurisprudencia constitucional anteriormente reseñados. ${ }^{98}$

Se requiere entonces de la configuración de una vía de hecho que viole un derecho

\footnotetext{
93 Corte Constitucional SU-174 de 2007.

94 Corte Constitucional. Sentencia C-378 de 2008.

95 Corte Constitucional. Sentencia T-058 de 2009.
}

96 Corte Constitucional. Sentencia T-408 de 2010. Ver igualmente: Consejo de Estado. Sección cuarta. Febrero 4 de 2010.

97 Corte Constitucional. Sentencia T-466 de 2011.

98 Ibid. 
fundamental. Se dice que el recurso de anulación sirve como mecanismo para proteger y corregir los vicios y defectos procesales del laudo. La acción de tutela serviría en caso de violación grave al derecho sustantivo.

\subsubsection{La relación entre el recurso de anulación y la acción de tutela}

En el año 2002 la Corte Constitucional indicó que la acción de tutela solo procede cuando se han hecho uso de los recursos provistos por el ordenamiento jurídico para controlar los laudos y cuando, a pesar de ello, subsiste una vulneración a un derecho fundamental ${ }^{99}$. La vía de hecho se configura ante la existencia de un error enorme y manifiesto del juzgador, ya sea juez nacional o árbitro. Se aplica un criterio de razonabilidad de la decisión del tribunal arbitral, si la decisión ha sido tomada completamente por fuera del procedimiento legal o convencional se configuraría la vía de hecho ${ }^{100}$. Algunos ejemplos que se han desarrollado en la práctica son la indebida apreciación del acervo probatorio, la violación al debido proceso o la aplicación manifiestamente equivocada de la ley.

Una de las preguntas que se han planteado tiene que ver con la procedibilidad de la acción de tutela en caso que todavía se pueda ejercer, o se encuentre en curso, el recurso de anulación o el de revisión del laudo arbitral. Las altas cortes han cambiado de posición una y otra vez.

Se encuentra así un conjunto de decisiones en donde se dice claramente que la acción de tutela solo es procedente si ya se ejercieron los recursos previstos en la ley contra el laudo arbitral y la vulneración al derecho sigue existiendo ${ }^{101}$. Como consecuencia la acción de tutela es una acción residual y subsidiaria, que solo debe proceder cuando no existen otros medios para proteger el derecho vulnerado ${ }^{102}$.

Sin embargo, se encuentra otro grupo de decisiones en donde se dice que la acción de tutela procede sin necesidad de agotar previamente

99 Corte Constitucional. Sentencia SU-837 de 2002. 100 Corte Constitucional. Sentencia T-408 de 2010. 101 Corte Constitucional. Sentencia T-839 de 2005.

102 Corte Constitucional. Sentencia T-608 de 1998. Ver igualmente: Corte Constitucional. Sentencia SU-837 de 2002 y T-244 de 2007 los recursos existentes, en el caso de que el vicio invocado no se encuentre en las causales taxativas disponibles para los recursos de anulación o de revisión ${ }^{103}$.

La Corte Constitucional señaló en el 2009 que:

En todo caso, es preciso anotar que en virtud de los artículos 8 y 9 del Decreto 2591 de 1991 y la jurisprudencia de esta Corporación, la acción de tutela puede ser presentada de manera simultánea con otras acciones administrativas o judiciales, pues la finalidad y alcance de estas acciones son diferentes, los fundamentos de las mismas no necesariamente guardan relación entre sí y los jueces de conocimiento tienen competencias y facultades precisas para decidir cada una de ellas. Así la cosas, se entiende que la interposición de la acción de tutela de manera simultánea con la presentación una acción o recurso, por si sola no hace improcedente la solicitud de amparo constitucional. ${ }^{104}$

Al existir vulneraciones graves al debido proceso, no alegables por medio del recurso de revisión o de anulación, al ser sus causales taxativas, se permitiría el uso de la acción de tutela de manera simultánea con la del recurso de anulación o revisión.

Esto implicaría igualmente que, en principio, si el recurso de revisión o de anulación se encuentra en curso, y se alega por medio de la tutela una causal que encaja dentro de algunos de los recursos mencionados, no procedería la acción. Lo cual no impediría su utilización una vez agotados y decididos los recursos pertinentes, si se considera que la vulneración aún existe.

Así como resulta un poco extraño para los juristas internacionales el conocer los grandes poderes que ostenta la Corte Constitucional en nuestro país, para los juristas nacionales también resulta preocupante y en ocasiones totalmente frustrante el observar que la Corte maneja a su antojo la Carta de derechos para justificar sus decisiones sobre la base de principios que solo ellos se encargan de alimentar ${ }^{105}$. En Sentencia

103 Corte Constitucional. Sentencia T-920 de 2004, SU-174 de 2007 y T-058 de 2009.

104 Corte Constitucional. Sentencia T-058 de 2009.

105 MANTILLA, Fabricio \& ONATE ACOSTA, Tatiana. La "dignidad" de la Corte Constitucional. 2013. Inédito. 
T-225 del 2010, la Corte dijo que por medio de la tutela no solo se podía controlar los laudos arbitrales sino también la providencia que resuelve un recurso de anulación contra un laudo arbitral $^{106}$.

En el año 2013 la Corte Constitucional tomó otra decisión aún más sorprendente, y que puede tener unas consecuencias nefastas para el arbitraje, al confirmar la decisión del Juzgado 37 Civil del Circuito de Bogotá de tutelar el derecho fundamental al debido proceso, dejando sin efecto las actuaciones del tribunal de arbitramento por falta de competencia ${ }^{107}$.

En el año 2012 se presentó una acción de tutela con el fin de proteger el derecho fundamental del debido proceso, presuntamente vulnerado por un tribunal arbitral en un litigio en la Cámara de Comercio de Bogotá. El principal argumento giraba en torno a la falta de competencia del tribunal para conocer del asunto al existir un acta de conciliación anterior entre las partes, anterior a la declaratoria de competencia del tribunal, que había hecho tránsito a cosa juzgada y que dirimía el conflicto.

El accionante indicó que no contaba con otro medio de defensa puesto que la existencia de la cosa juzgada no es una causal de anulación del laudo. Hay que tener en cuenta que lo que se atacaba por medio de la acción de tutela, seis meses después del pronunciamiento, era el acto de declaración de competencia del tribunal arbitral.

El laudo no había sido todavía proferido así que no se conocía la decisión del tribunal respecto de la excepción de cosa juzgada y, después de proferido el laudo, todavía estaría disponible el recurso de anulación y, eventualmente, el de revisión contra el laudo. Como se recalcó antes en este escrito, la tutela es un recurso subsidiario en donde la inmediatez juega un papel imprescindible.

Sin embargo, el hecho de que la tutela fuera interpuesta seis meses después de la declaratoria de competencia desvirtúa el peligro inminente al derecho fundamental alegado; esto sin olvidar

106 Corte Constitucional. Sentencia T-225 de 2010.

107 Corte Constitucional. Sentencia T-288 de 2013. Mayo 20 de 2013. Salvamento de voto de Magistrado Luis Ernesto Vargas. que aún no se tenía un pronunciamiento del tribunal arbitral y que el carácter subsidiario de la acción de tutela no se cumpliría, dada la existencia de otros recursos contra un eventual laudo desfavorable en contra del accionante en tutela.

Empero, según las mismas consideraciones de la Corte, el caso no encajaba en ninguna de las causales eventuales del recurso de anulación, razón por la cual el único medio idóneo restante para proteger el derecho al debido proceso era la tutela. Que la tutela se presentará seis meses después tampoco pareció haber sido considerado por el juez constitucional.

Esta decisión constituye una vulneración al principio de la autonomía de la cláusula compromisoria. En efecto, los árbitros están habilitados para pronunciarse en caso de existencia de una cláusula compromisoria sin importar si el contrato es inexistente, nulo o ineficaz. La cláusula compromisoria subsiste a pesar de que el contrato sufra de algún vicio.

El hecho de que la existencia del contrato se ponga en duda no impide que el tribunal arbitral se declare competente y en el futuro se pronuncie sobre las pretensiones de las partes.

Es así que la decisión del juez, la cual dejo sin efectos todo lo transcurrido después de la declaratoria de competencia, sobre el fundamento de que existía una conciliación anterior, implica no solo una revisión de fondo por parte de los jueces, lo cual estaría prohibido, sino una violación a los principios base del arbitraje.

Otro principio que se ve vulnerado es el de competencia-competencia que habilita a los árbitros a pronunciarse sobre su propia competencia. Si el juez de tutela puede juzgar, sobre el fundamento de la existencia de derecho fundamentales vulnerados, la pertinencia de la declaratoria de competencia del tribunal de arbitraje, existiría un control posterior creado por jurisprudencia que no se encuentra en la Ley, y esto a pesar de que existen medios legales para atacar las decisiones de los árbitros contemplados antes y después de la Ley 1563 de 2012.

La sentencia T-288 recuerda lo que considera son los requisitos de procedibilidad de la acción de tutela: 
a. Que la cuestión que se discuta resulte de evidente relevancia constitucional... b. Que se hayan agotado todos los medios -ordinarios y extraordinarios- de defensa judicial al alcance de la persona afectada, salvo que se trate de evitar la consumación de un perjuicio iusfundamental irremediable... c. Que se cumpla el requisito de la inmediatez, es decir, que la tutela se hubiere interpuesto en un término razonable y proporcionado a partir del hecho que originó la vulneración... d. Cuando se trate de una irregularidad procesal, debe quedar claro que la misma tiene un efecto decisivo o determinante en la sentencia que se impugna y que afecta los derechos fundamentales de la parte actora... e. Que la parte actora identifique de manera razonable tanto los hechos que generaron la vulneración como los derechos vulnerados y que hubiere alegado tal vulneración en el proceso judicial siempre que esto hubiere sido posible... f. Que no se trate de sentencias de tutela. ${ }^{108}$

De la misma manera la alta Corte recuerda los requisitos especiales de procedibilidad excepcional de la acción de tutela:

a. Defecto orgánico, que se presenta cuando el funcionario judicial que profirió la providencia impugnada, carece, absolutamente, de competencia para ello. b. Defecto procedimental absoluto, que se origina cuando el juez actuó completamente al margen del procedimiento establecido. c. Defecto fáctico, que surge cuando el juez carece del apoyo probatorio que permita la aplicación del supuesto legal en el que se sustenta la decisión. d. Defecto material o sustantivo, como son los casos en que se decide con base en normas inexistentes o inconstitucionales [25] o que presentan una evidente y grosera contradicción entre los fundamentos y la decisión. e. Error inducido, que se presenta cuando el juez o tribunal fue víctima de un engaño por parte de terceros y ese engaño lo condujo a la toma de una decisión que afecta derechos fundamentales. f. Decisión sin motivación, que implica el incumplimiento de los servidores judiciales de dar cuenta de los fundamentos fácticos y jurídicos de sus decisiones en el entendido que precisamente en esa motivación reposa la legitimidad de su órbita funcional. g. Desconocimiento del precedente, hipótesis que se presenta, por ejemplo, cuando la Corte Constitucional establece el alcance de un derecho fundamental y el juez ordinario aplica una

108 Ibid. ley limitando sustancialmente dicho alcance...h Violación directa de la Constitución. ${ }^{109}$

La decisión en el seno de la Corte no fue unánime y se encuentra un salvamento de voto del Dr. Luis Ernesto Vargas, en donde señala que la acción debió ser declarada improcedente al existir otros recursos ordinarios contra la decisión de los árbitros.

Asimismo, señaló que el accionante no había logrado probar la existencia de un perjuicio irremediable que "tornara procedente de forma transitoria la acción de tutela". Añade que tal y como se esperaba, durante el trámite de impugnación de la acción de tutela el tribunal profirió un laudo que fue atacado por recurso de anulación. Que la Sala Civil del Tribunal Superior de Bogotá hubiera aceptado el recurso de anulación demostraba que existían otros recursos viables para atacar la decisión del tribunal. El problema radicó en que el Tribunal Superior de Bogotá no se pudo pronunciar sobre el recurso de anulación, dado que la decisión constitucional había dejado sin efectos todas las actuaciones arbitrales con posterioridad a la declaratoria de competencia.

La acción de tutela contra laudos arbitrales había sido aceptada desde antes de la sentencia T-288 de 2013, sin embargo, las implicaciones de esta última decisión parecen ser mucho más graves. Antes la tutela se aceptaba de manera muy excepcional, a partir de esa sentencia se abren las puertas para que los practicantes empiecen a intentar cada vez más la acción de tutela como medio idóneo de proteger los derechos de sus clientes. Si el alto Tribunal lo permite, ¿por qué los abogados no habrían de utilizarlo?

Ahora bien, no solo se vulnera el principio de competencia-competencia y el de la autonomía de la cláusula compromisoria, sino que el juez se toma la libertad de realizar un control sobre el fondo del laudo. En efecto, cuando el juez constitucional entra a determinar si la conciliación anterior a la conformación del tribunal es parcial o definitiva no está realizando un simple control de forma ni un control del "derecho fundamental del debido proceso", en realidad está realizando una revisión de fondo. 
Como si fuera poco "deja sin efectos" todas las actuaciones del tribunal aun antes de que este se haya pronunciado. El pretexto de que en el caso en concreto no se podía atacar el laudo a través de las causales disponibles en el recurso de anulación no es totalmente valido, es el abogado aquel que debe saber cómo encausar sus pretensiones, y en el caso de que tenga la astucia de intentar desviarse a través de la acción de tutela, debería ser el juez constitucional el encargado de regresarlo a su sitio, y no de incentivarlo a crear nuevas instancias de revisión de laudos arbitrales.

\section{4 ¿La procedencia de la tutela en el arbitraje internacional?}

Todos los casos anteriormente mencionados implican al arbitraje nacional en Colombia, ahora cabe preguntarse, ¿qué incidencia tienen sobre el arbitraje internacional? Para el Dr. Eduardo Zuleta en principio sería limitada ${ }^{110}$. La Ley 1563 de 2012 contiene los casos en los cuales se permite la intervención judicial en el arbitraje.

La ley arbitral contiene, en la sección tercera, sobre arbitraje internacional, los casos taxativos en que los jueces están autorizados a intervenir. El estatuto no excluye de manera expresa la tutela en el arbitraje internacional, lo cual es lamentable ya que no nos encontraríamos ante el eventual escenario de ver un laudo internacional anulado por una tutela.

Un sector de la doctrina considera que no se prohibió de manera expresa, dado que una ley no puede excluir un precepto de carácter constitucional, sin embargo, la forma en que está organizada la ley podría excluirla al no estar expresamente admitida para el arbitraje internacional. Adicionalmente, pueden desarrollarse otros argumentos en contra de la admisibilidad de la tutela en el arbitraje internacional en Colombia.

Uno de los fundamentos de procedibilidad de la acción de tutela en el arbitraje doméstico es el hecho de equiparar a los árbitros con las autoridades judiciales o públicas, sin embargo, un tribunal internacional con sede en Colombia no podría ser calificado de autoridad pública,

110 ZULETA, Eduardo. La colaboración de los jueces en el arbitraje internacional. En : Estatuto arbitral colombiano. Análisis y aplicación de la Ley 1563 de 2012. Legis. 2013. Pp. 496 yss. ni asumirse que dicta el laudo a nombre del Estado y que por esto se pueda generar una responsabilidad del Estado colombiano.

La competencia de los árbitros no sería una consecuencia de la ley colombiana, al dictar el laudo, este no se convierte en un laudo colombiano. Los árbitros internacionales no se encuentran sujetos al lugar de la sede del arbitraje y las partes son las que pactan cuál es el derecho aplicable a la disputa.

El arbitraje puede tener sede en Colombia, siendo que todos los otros puntos de contacto no tienen nada que ver con nuestro país. El artículo 79 y 107 de la Ley 1563 solo permite el recurso de anulación contra un laudo internacional, renunciable en los casos en que ninguna de las partes tenga su domicilio o residencia en Colombia.

A pesar de estas consideraciones, la Corte Constitucional ha demostrado no escatimar ningún esfuerzo para construir las teorías, sobre el fundamento de los derechos fundamentales y los principios constitucionales, que le sirvan para justificar las decisiones que toman, y esto sin importar que vaya en contra de las otras altas Cortes o que la ley no contenga lo que ellos quieren que contenga.

A pesar de esto seguimos encontrando decisiones sensatas que limiten el uso de la tutela, como la Sentencia del Consejo de Estado del 24 de enero de $2013^{111}$, en donde se reafirma que el proceso arbitral es el lugar idóneo para resolver las disputas, y en donde se insiste que la cláusula compromisoria muestra la voluntad de las partes de resolver la controversia ante el tribunal arbitral y no ante los jueces ordinarios. Los recursos disponibles contra el laudo deben ser los medios idóneos para atacarlo y la tutela debe seguir siendo una herramienta verdaderamente excepcional, que debería ejercerse sólo después de agotados los recursos contra el laudo.

\section{CONCLUSIÓN}

El nuevo Estatuto arbitral mejoró el arbitraje nacional e internacional en Colombia, aunque no

111 Consejo de Estado. SCA. Sección segunda. Subsección B. Enero 24 de 2013. Radicación número: 25000-23-42-000-201201017-01(AC). C.P. Gerardo Arenas Monsalve. 
logró llenar todos los vacíos legales. Un estudio de la embajada de Estados Unidos, anterior a la nueva Ley y dirigido a las empresas norteamericanas, muestra algunos de los peligros del arbitraje comercial internacional $\mathrm{y}$ de inversiones en Colombia ${ }^{112}$.

Sin embargo, este estudio no toma en cuenta la Ley 1563 de 2012, en donde se separa los regímenes del arbitraje nacional e internacional para darle una mayor seguridad al arbitraje internacional e impulsar una nueva era en Colombia como sede del arbitraje en
Latinoamérica. De pronto hubiera sido mejor tener un régimen monista del arbitraje, pero la práctica en el país muestra que hay que atender y conservar las particularidades del arbitraje nacional.

Esto puede terminar jugando a favor del arbitraje internacional, desprendiéndose de los viejos enemigos que aquejan al arbitraje nacional. Solo el futuro del arbitraje internacional en Colombia demostrará si en realidad está tan protegido como se intentó en el nuevo Estatuto.

112 U.S. Embassy Bogotá-Colombia. An overview of arbitration in Colombia for U.S. Companies. Mayo 2011. Disponible en :http:// export.gov/colombia/static/Report\%20-\%20Arbitration\%20 in 20 Colombia\%20-\%20final\%206-1-11_Latest_eg_ co_033097.pdf

\section{BIBLIOGRAFÍA}

- GOMEZ JENE, Miguel. El arbitraje internacional en la Unión Europea: La eficacia del laudo arbitral, Madrid, Editorial Colex, 2000, p. 104.

- CADARSO PALAU, Juan. Potestad de los Árbitros para decidir sobre su Competencia. En: Comentarios a la Nueva Ley de Arbitraje 60/2003, de 23 de diciembre. Navarra. Editorial Aranzadi S.A. 2004. Páginas 265-266

- HOLTZMAN y NEUHAUS, A Guide to the UNCITRAL Model Law in Internacional Comercial Arbitration, Kluwer (1989)

- FOUCHARD Philippe, GAILLARD Emmanuel \& GOLDMAN Berthold. L'autonomie de l'arbitre international dans l'appréciation de sa propre compétence, en Collected Courses of the Hague Academy of International Law, Vol. 217, 1989, Parte 5 Pag 319.

- FOUCHARD Philippe, GAILLARD Emmanuel \& GOLDMAN. On International Commercial Arbitration" La Haya, Kluwer law international. 1999 Nota 7, página 393.

- DE BOISSEISON, M. "Le droit français de l'arbitrage interne et international. GLN Joly Edition. Pag 777 y 778.
- HENRY, M. Le devoir d'indépendance de l'arbitre. Editorial L.G.D.J, 2001.

- JIMENEZ FIGUERES, Dyalà Jimenez. Renuncia al recurso de anulación contra el laudo: Alcances y análisis comparativo. Arbitraje comercial y arbitraje de inversión. Páginas 531-537.

- DE JESUS 0, Alfredo. La autonomía del arbitraje comercial internacional a la hora de la constitucionalizacion del arbitraje en América Latina. Publicado en Estudios de derecho privado en Homenaje a Christian Larroumet. Universidad del Rosario, Bogotá, 2008.

- LARRAUMET Christian, (Dir.), Constitucionalización del Derecho Privado, Association Andrés Bello des juristes francolatino-américains - Universidad Externado de Colombia - Universidad del Rosario, Bogotá, 2007.

- ZULETA LONDOÑO, Alberto. La protección constitucional del arbitraje. EN : Arbitraje Internacional - Tensiones Actuales. Fernando Mantilla-Serrano. Legis. 2007

- MANTILlA, Fabricio \& ONATE ACOSTA Acosta, Tatiana. La "dignidad" de la Corte Constitucional. 2013. Inédito 
- ZULETA, Eduardo. La colaboración de los jueces en el arbitraje internacional. En: Estatuto arbitral colombiano. Análisis y aplicación de la Ley 1563 de 2012. Legis. 2013. Pp. 496 y ss.

\section{Reglamentos y tratados internacionales}

- Ley Modelo de la CNUDMI sobre Arbitraje Comercial Internacional 1985 con las enmiendas aprobadas en 2006

- Protocolo de Ginebra de 1923 relativo a las cláusulas de arbitraje en materia comercial

- Reglamento de arbitraje de la AFA

- Reglamento de la CCI 2012 sobre el arbitraje

- Convención de New York de 1958 sobre el reconocimiento y la ejecución de las sentencias extranjeras.

- Revistas especializadas

- GAILLARD, Emmanuel y DE LAPASSE Pierre, Commentaire analytique du décret du 13 janvier 2011 portant réforme du droit français de l'arbitrage, Cahiers de l'Arbitrage (2011) 2. pag. 263.

- VASQUEZ PALMA, Maria Fernanda. Comprensión del principio CompetenciaCompetencia y configuración de la nulidad o ineficacia del acuerdo arbitral. Revista Chilena de Derecho Privado, $N^{\circ} 15$, pp. 181196. Diciembre 2010].

- CONEJERO ROOS, Cristian. "La influencia de la ley modelo de la CNUDMI sobre arbitraje comercial internacional en américa latina: un análisis comparativo". Revista Chilena de Derecho, vol. 32, núm. 1, enero-abril, 2005, pp. 89-138, Pontificia Universidad Católica de Chile.

- FOUCHARD, Philippe de la Sentencia de la Corte de Apelaciones de Paris de 18 de noviembre de 1987. Chambre arbitrale de Paris v. République de Guinée, 1988. Revista de arbitraje numero 657
- Tribunal de « Grande instance » 15 de 1995, Industrial export v K. REV.ARB. número 503 de 1995. Nota de FOUCHARD, Philippe.

- GAILlARD, Emmanuel, Les manœuvres dilatoires des parties et des arbitres dans l'arbitrage commercial international, 1990 REV. ARB. Especialmente en Pp. 761 y siguientes.

- VEEDER, VV, L'affaire du tunnel sous la manche et les mesures conservatoires, 1993 REV. ARB. 705.

- JARRONSON Ch., PELLERIN, J. Le droit Français de l'arbitrage après le décret du 13 janvier 2011. REV. ARB. 2011. 5 especial, pag 16.

- Corte de apelaciones de Paris, 19 de diciembre de 1982. REV ARB, 1983. 181, nota de MOREAU, B.

- Corte de Casación. Sala primera civil, 20 de marzo de 1989, REV ARB., 1989. 494, 3 nota de COUCHEZ , G.

- Corte de Casación. Sala Civil 2, 29 de noviembre de 1989 y 6 de marzo de 1990. 633, nota GAUDEMENT-TALLON GH.

- Corte de apelaciones de París, 30 de enero 1992 y Corte de apelaciones de Versalles, 22 de mayo de 1992, REV ARB 1992.666, obs. MOIRTRY J-H.

- Corte de apelaciones de Paris 7 octubre de 2004, JCP G 2005. II. 10071, nota de JACQUET J.M.

- Corte de apelaciones de Rennes, 26 de octubre de 1984, REV. ARB. 1985. Pagina 439.

- COUCHEZ G., Compare, as regards « référé provision ", Corte de Casacion. Sala 2 Civil. , Marzo 20 de 1989. Danel v Sotiat Informatique, 1989 REV. ARB. 494.

- Casación civil 1, 7 de enero de 1992, Rev, arb., 1992 471, nota BELLET, P.; JDI, 1992. 707. Nota JARRONSON, Ch.

- CLAY, T. La disparition de l'obligation d'indépendance de l'arbitre au profit de l'obligation de révélation. REV. ARB. 2009.190. 
- Casación Civil, Sala primera, 23 de marzo de 1994, REV. ARB. 1994.327, nota JARRONSON Ch; Rev. Crit. DIP., 1995. 956, nota OPPETIT B.; JDI, 1994. 701.

- GAILLARD, Emmanuel. L'exécution des sentences annulées dans leur pays d'origine, Journal du Droit international, 125" année (1998) No 3 - Juillet-Août-Septembre.

- Société Pabalk Ticaret Ltd. Sirketi v. Société Norsolor. Corte de Casación de París (9 de octubre, 1984), 2 Journal of International Arbitration, 67. XI Yearbook of Commercial Arbitration, YBCA, 484 (1986). 24 International Legal Materials, ILM, 360 (1985).

- PT Putrabali Adyamulia v. Rena Holding. Nos. 05-18053 y 06-13293, Corte de Casación (29 de junio, 2007). I Bulletin Civil, 250, 251. Revue de l'Arbitrage, 507 (2007).

- MANTILLA-SERRANO Fernando. Panorama de jurisprudencia francesa (Capítulo francés del Club Español del Arbitraje): Comentario sobre la decisión de la Cour d'Appel (1 1 a Sala Civil) de 29 de junio de 2007 PT Putrabali Adyamulia c. Rena Holding, 3 Spain Arbitration Review, 106 (2008).

- MANTILlA SERRANO Fernando, Algunos apuntes sobre la ejecución de los laudos anulados y la convención de Nueva York. Int. Law: Rev. Colomb. Derecho Int. no.15 Bogotá July/Dec. 2009.

- BERNAL GUTIERREZ Rafael, "El arbitraje internacional dentro del nuevo estatuto del arbitraje en Colombia", XXXIII Congreso Colombiano de derecho procesal, Universidad libre de Colombia, páginas 280 y siguientes.

- Textos legales

- Decreto no 2011-48 del 13 de enero del 2011 sobre la reforma del arbitraje, J0, 14 enero 2011

- Código de procedimiento civil francés.

- Ley 1563 de 2012
- Ministerio del interior y de la Justicia. República de Colombia. Congreso de la República. Proyecto de ley de 2011

- Constitución Política de Colombia de 1991.

- Jurisprudencia Francesa

- Corte de Casación. Primera sala civil. 14 de noviembre de $2007 n^{\circ} 06 / 21.629$.

- Corte de Apelaciones de Paris, 6 febrero de 1991, Groupe Courtand c/ Société Beam Morin, inédito.

- Corte de Casación. Primera sala civil, 1 de febrero de 2007, BICC N 663, de 15 junio de 2007.

- Corte de Apelaciones de Paris, Pôle 2, Primera sala, 1èr de marzo de 2011, ${ }^{\circ}$ 09/22701

- Corte de Apelaciones de Paris. Primera sala, sect C. Nov 1977, n 96/82828.

- Corte de apelaciones de Paris. Primera sala , sect, 10 avr. 2008, nº 06/15636

- Corte de Casación. Primera sala civil. Arrêt $\mathrm{n}^{\circ} 962$ del 20 de octubre 2010, ${ }^{\circ}$ 09/ 68.131.

- Corte de Casación. Primera sala civil. Arrêt $n^{\circ} 963$ del 20 de octubre $2010 n^{\circ}$ 09/ 68.997

- Corte de apelaciones de Paris, pôle 1, Ch 1, 10 de marzo de 2011 RG n ${ }^{\circ}$ 09/21413

- Corte de Casación, 8 de julio de 2009, "Soemi c/ société Air Sea Broker Ltd".

- Corte de Casacion, 9 de marzo de 2011, Société Chantiers de l'Atlantique (CAT) /Société Gaz Transport et Tecnigaz (GTT).

- Jurisprudencia Colombiana

- Corte Constitucional.Sentencia T- 288/2013

- Corte Constitucional, Sentencia de C-431/95 de 1998

- Consejo de Estado. SCA. Sección tercera. Primero de agosto de 2002. Electrificadora del Atlántico S.A. E.S.P. contra Termorio S.A. E.S.P.

- Corte Constitucional. Sentencia SU-837 de 2002. 
- Consejo de Estado. SCA. Sección tercera. 11 de marzo de 2004.

- Corte Constitucional. Sentencia T-481 del 11 de mayo de 2005. Exp. T-980611. Sin embargo, esta decisión fue revocada mediante Sentencia de la misma Corte Constitucional SU-174 de 2007.

- Corte Constitucional SU-174 de 2007.

- Corte Constitucional. Sentencia C-378 de 2008.

- Corte Constitucional. Sentencia T-058 de 2009.

- Corte Constitucional. Sentencia T-408 de 2010.

- Consejo de Estado. Sección cuarta. Febrero 4 de 2010.

- Corte Constitucional. Sentencia T-466 de 2011.

- Corte Constitucional. Sentencia SU-837 de 2002.

- Corte Constitucional. Sentencia T-408 de 2010.

- Corte Constitucional. Sentencia T-839 de 2005.

- Corte Constitucional. Sentencia T-608 de 1998.
- Corte Constitucional. Sentencia SU-837 de 2002 y T-244 de 2007.

- Corte Constitucional. Sentencia T-920 de 2004, SU-174 de 2007 y T-058 de 2009.

- Corte Constitucional. Sentencia T-225 de 2010.

- Corte Constitucional. Sentencia T-288 de 2013. Mayo 20 de 2013. Salvamento de voto de Magitrado Luis Ernesto Vargas.

- Consejo de Estado. SCA. Sección segunda. Subsección B. Enero 24 de 2013. Radicación número: 25000-23-42-000-2012-0101701(AC). C.P. Gerardo Arenas Monsalve.

- Articulos internet

- ROQUE J CAIVANO, Retos del arbitraje frente a la administración de justicia, disponible en: http://www.castillofreyre. com/biblio_arbitraje/vol5/DIA-1-2.pdf.

- Reportes y estadísticas

- 1. CCI, Reporte estadístico, 14 (1) ICC. Ct. Boletín, 7, 11 (2003) - Reporte stadístico2006, 18 (1) ICC. Bull. 5, 9 (2007).

- 2. U.S. Embassy Bogotá-Colombia. An overview of arbitration in Colombia for U.S. Companies. Mayo 2011. 